\title{
On the Role of Heterojunctions of Core-Shell Heterostructures in Gas Sensing
}

Muhammad Hamid Raza ${ }^{1}$, Roberto Di Chio ${ }^{2}$, Kaveh Movlaee ${ }^{2}$, Patrick Amsalem³ ${ }^{3}$ Norbert Koch ${ }^{3,4}$, Nicolae Barsan ${ }^{5}$, Giovanni Neri ${ }^{2}$, Nicola Pinna ${ }^{1^{*}}$

1 -Institut für Chemie and IRIS Adlershof, Humboldt-Universität zu Berlin, Brook-Taylor-Str. 2, 12489 Berlin, Germany

2 -Department of Engineering, University of Messina, C.Da Di Dio, I-98166 Messina, Italy

3 -Institut für Physik and IRIS Adlershof, Humboldt-Universität zu Berlin, Brook-Taylor-Str. 2, 12489 Berlin, Germany

4 -Helmholtz-Zentrum Berlin GmbH, Albert-Einstein-Str. 15, 12489 Berlin, Germany

5 - Institute of Physical and Theoretical Chemistry, University of Tübingen, Auf der Morgenstelle 15, 72076 Tübingen, Germany

* Corresponding Author E-mail: nicola.pinna@hu-berlin.de 
Abstract: Heterostructures made from semiconducting metal oxides (SMOX) are fundamental for the development of high-performance gas sensors. Yet, despite the recognition of their importance in real applications, the understanding of the transduction mechanism either related to the heterojunction, or simply to the core and shell materials is still lacking. A better understanding of the sensing response of heterostructured nanomaterials requires the engineering of heterojunctions with well-defined core and shell layers. Here, we introduce a series of prototypes ${ }_{n} S M O X-C N T,{ }_{p} S M O X-C N T$, and ${ }_{p} S M O X-$ ${ }_{n} S M O X-C N T$ and ${ }_{n} S M O X-p S M O X-C N T$ hierarchical core-shell heterostructures (CSHS) permitting us to directly relate the sensing response to the SMOX shell, or to the p-n heterojunction. The carbon nanotubes are here used as highly conductive substrates permitting to operate the devices at relatively low temperature and are not involved in the sensing response. $\mathrm{NiO}$ and $\mathrm{SnO}_{2}$ are selected as representative $p$ - and n-type SMOX, respectively, and the response of a set of samples is studied toward hydrogen considered as model analyte. The ${ }_{n, p} S M O X-C N T$ CSHS exhibit response related to the ${ }_{n, p} S M O X$-shell layer. On the other hand, the ${ }_{p} S M O X{ }_{n} S M O X-C N T$ and ${ }_{n} S M O X-{ }_{p} S M O X-C N T C S H S$ show sensing responses, which in certain cases are governed by the heterojunctions between ${ }_{n} S M O X$ and ${ }_{p} S M O X$ and strongly depends on the thickness of the SMOX layers. Due to the fundamental nature of this study, these findings are important for the development of next generation gas sensing devices.

1D, 2D, and 3D semiconducting metal oxides (SMOX)-based hetero-nano-structures are presently highly studied in resistive sensing applications. ${ }^{[1]}$ A plethora of SMOX hetero-nano-structures has been reported and in many cases the sensing response has been attributed to the heterojunction. ${ }^{[1,2]}$ Although many studies identify chemo-resistive heterostructures as having enhanced sensing properties, a comprehensive mechanistic understanding of these materials is still lacking. ${ }^{[1, \mathrm{~d}, \mathrm{i}, 3]}$ The improvement of the gas-sensing properties of these heterostructures has been referred to various factors comprising electronic, chemical and geometrical effects. ${ }^{[1-\mathrm{a}-\mathrm{g}, 2-3,4]}$ Among the electronic effects, enhanced gas sensing properties have been also assigned to the semiconductor heterojunctions at $n-n$, $p$ - $p$, or $p$ - $n$ interfaces. ${ }^{[1,2-23]}$ This is due to the difference in the Fermi energies $\left(\mathrm{E}_{\mathrm{F}}\right)$ of the two semiconducting materials in contact, where the electrons at the higher energy level flow across the interface to unoccupied lower-energy states. ${ }^{[1 \mathrm{j}, 3 \mathrm{~b}]}$ This is related to the electron-hole recombination at a $p$ - $n$ junction and is referred as "Fermi level-mediated charge transfer". ${ }^{[1,3 b, 5]}$ As a result, the energy bands bend at the interface and an electron depletion layer is formed. In this context, although semiconductor heterostructures exhibit peculiar gas sensing properties the understanding of the transduction across these interfaces as well as the simulated response is still missing. ${ }^{[1,3 a, 4-5]}$ One of the main reasons is due to the fact that in gas sensing the semiconductor heterostructures employed are often ill-defined, ${ }^{[1 \mathrm{f}, \mathrm{i}, \mathrm{j}, 3 \mathrm{a}]}$ for example when both materials expose their surface to the analytes, e.g. when the core is not completely covered by a uniform and conformal shell layer. ${ }^{[1]]}$ Furthermore, the analytes may react with one of the two materials preferentially and the by-products with the other. ${ }^{[1 \mathrm{~d}, \mathrm{~g}, 3 \mathrm{a}, 4-5]}$ Therefore, in order to properly understand the reactivity of the sensor materials and the whole transduction mechanism, the design of well-defined and well-controlled heterostructured materials at the nanoscale is required..$^{[1 \mathrm{~g}, 3 \mathrm{a}, \mathrm{b}, \mathrm{d}, 4-5]}$

Indeed, the sensing responses of heterostructured materials discussed in the literature are very disparate and not always related to the $p-n$ semiconductor heterojunction, ${ }^{[1, \mathrm{~h}, \mathrm{hb}, 4]}$ but could be limited to the core or the shell material. ${ }^{[4,6]}$ For example, it was demonstrated that even by depositing a second material conformally onto already contacted (core-core junctions) $1 \mathrm{D} \mathrm{SnO}_{2}$ nanowires $\left(\mathrm{SnO}_{2}\right.$-core) or carbon nanotubes (CNTs-core) modifies both the width and the thickness of the depletion region at the interface, but the sensing responses were exclusively attributed to the core materials. ${ }^{[1,5 b, 7]}$ In that case, the shell-layers modified the surface of the already fabricated devices without dramatically modifying the underlying transduction mechanism. ${ }^{[1, \mathrm{c}, \mathrm{j}, 3 \mathrm{bb}, 4]}$ Alternatively, a change in the order of device/geometry and materials fabrication (e.g., by adding shell-shell junctions to the core-shell heterojunction, and omitting the direct core-core junction), could result in a response related to (i) the shell-layer, (ii) the core-axis, or (iii) the $p$-n interface. ${ }^{[3 a, b, 5 a, 8]}$ A study on NiO-CNT core-shell 
heterostructures (CSHS) demonstrated that the response was strongly related to the NiO-shell. ${ }^{[6]}$ Indeed, when an insulating alumina buffer layers was introduced between the NiO-shell and the CNTcore substrate, the transduction mechanism and the response were not affected, but only the baseline resistance of the device increased. These findings demonstrate that the NiO-CNT CSHS respond to different gases primarily through the shell-layer and the interface between the two materials does not play a determinant role. ${ }^{[6 a]}$

The present study is designed such as to elucidate the role of $p$ - $n$ heterojunctions in the sensing properties of SMOX-SMOX CSHS. A series of well-defined hierarchical CSHS composed of ${ }_{n}$ SMOX$\mathrm{CNT},{ }_{p} \mathrm{SMOX}-\mathrm{CNT}$, and ${ }_{p} \mathrm{SMOX}_{n} \mathrm{SMOX}-\mathrm{CNT}$ and ${ }_{n} \mathrm{SMOX}{ }_{p} \mathrm{SMOX}-\mathrm{CNT}$ prototypes (i.e., $\mathrm{SnO}_{2^{-}}$ CNT, NiO-CNT, NiO-SnO ${ }_{2}-\mathrm{CNT}$ and $\mathrm{SnO}_{2}-\mathrm{NiO}-\mathrm{CNT}$ ) are synthesized and their gas sensing properties are studied towards hydrogen chosen as model analyte. $\mathrm{SnO}_{2}$ and $\mathrm{NiO}$ are chosen as representative and among the most employed $n$ - and p-type SMOX, and CNTs as model 1D conductive substrate (core). ${ }^{[1,, 9]}$ Different thicknesses of the ${ }_{n, p}$ SMOX thin films are deposited using atomic layer deposition (ALD), the most suitable technique to deposit SMOX films with an Ångstromlevel thickness control onto high-aspect-ratio substrates such as CNTs. ${ }^{[10]}$ Conformal and homogeneous thin films of $\mathrm{SnO}_{2}$ and $\mathrm{NiO}$ with controlled thicknesses are deposited in an alternate fashion to clearly assign the type of sensing response to the $p$ - $\mathrm{NiO}$ or $n-\mathrm{SnO}_{2}$ allowing us to elucidate the sensing mechanism and the role of the heterojunction. A comprehensive of the synthesis process can be found in the experimental section in the supporting information (SI). Briefly, CNTs were functionalized following a procedure described in our previous reports. ${ }^{[1 j]}$ The functionalized CNTs were coated with conformal and homogeneous films of tin oxide and nickel oxide via ALD. NiO ALD was performed at $200{ }^{\circ} \mathrm{C}$ using bis(cyclopentadienyl)nickel(II) and ozone as Ni-precursor and oxygen source, respectively. $\mathrm{SnO}_{2}$ ALD was performed at $190{ }^{\circ} \mathrm{C}$ using tetrakis(dimethylamino)tin(IV) and ozone as Sn-precursor and oxygen source, respectively. The ALD conditions and parameters were optimized to ensure a conformal and homogeneous deposition (experimental-section in the SI). Scheme 1 represents the synthesis route for a series of different CSHS and fabrication of the sensing device. Table S1 displays the detail of all of the samples, and estimated thicknesses of $\mathrm{NiO}$ and $\mathrm{SnO}_{2}$ films with varying number of ALD cycles.

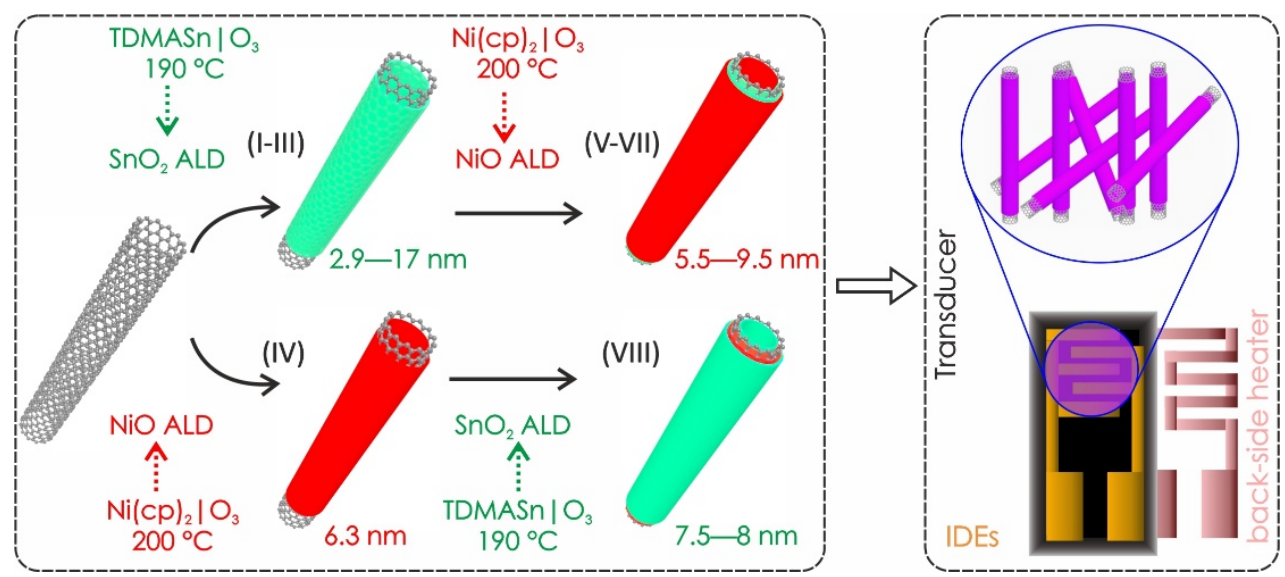

Scheme 1. A Presentation of the synthesis process of a series of $\mathrm{NiO}$ and $\mathrm{SnO}_{2}$-based core-shell heterostructures and the sensing device fabrication, where the numbers I- VIII correspond to the sample number in Table S1. The samples are specified by mentioning the number of ALD cycles as subscripted prefix with the sample name.

Powder X-ray diffraction (pXRD) patterns confirmed the deposition of cassiterite (tetragonal) and rock-salt cubic phases of crystalline $\mathrm{SnO}_{2}$ and $\mathrm{NiO}$, respectively (Figure $\mathbf{S 1}$ and the respective discussions in the SI, powder X-ray diffraction-section). The selected area electron diffraction (SAED) 
patterns further confirmed the presence of distinctive crystalline phases of cassiterite (tetragonal) and rock-salt cubic $\mathrm{SnO}_{2}$ and NiO, respectively (Figure 1aIII-fIII). The corresponding concentric rings in the SAED patterns recorded for the samples in the same panels-row confirm the polycrystalline character of all of the respective coatings of $\mathrm{SnO}_{2}$ and $\mathrm{NiO}$. The main Debye-Scherrer rings for $\mathrm{NiO}$ samples (panels III in Figure 1a, c-f) correspond to the (111), (200) and (220) planes of the cubic (rock-salt) structure of $\mathrm{NiO}$ (ICDD: 00-073-1523). The main Debye-Scherrer rings for $\mathrm{SnO}_{2}$ samples (panels III in Figure 1b-f) correspond to the (110), (101), (211) and (310) planes of the cassiterite structure of $\mathrm{SnO}_{2}$ (ICDD: 00-003-0439). The SAED patterns for ${ }_{Y} \mathrm{SnO}_{2-}{ }_{X} \mathrm{NiO}-\mathrm{CNT}$ and ${ }_{X} \mathrm{NiO}-{ }_{Y} \mathrm{SnO}_{2}{ }^{-}$ CNT ( $x$ and $y$ being the number of ALD cycles of the $\mathrm{NiO}$ and $\mathrm{SnO}_{2}$ process, respectively) correspond to both of the cubic and cassiterite phases of $\mathrm{NiO}$ and $\mathrm{SnO}_{2}$. This shows that both of the $\mathrm{NiO}$ and $\mathrm{SnO}_{2}$ are deposited in their respective crystalline structures onto the CNT, NiO-CNT, and $\mathrm{SnO}_{2}-\mathrm{CNT}$ substrates, while preserving the substrate structure ( $c$. Figure S1, pXRD) ${ }^{[3 b]}$ In addition, all of the SAED patterns show the reflections correspond to the (002) hexagonal plane for the graphitized carbon in the CNTs. Figure S2 shows the bright-field transmission electron microscopy (BF-TEM) micrographs of as-synthesized ${ }_{200} \mathrm{NiO}-\mathrm{CNT},{ }_{20} \mathrm{SnO}_{2}-\mathrm{CNT},{ }_{50} \mathrm{SnO}_{2}-\mathrm{CNT},{ }_{100} \mathrm{SnO}_{2}-\mathrm{CNT},{ }_{200} \mathrm{NiO}_{50} \mathrm{SnO}_{2}-$ $\mathrm{CNT}$ and ${ }_{350} \mathrm{NiO}_{-50} \mathrm{SnO}_{2}$-CNT CSHS. The inner and outer walls of the CNTs are conformally and uniformly coated with $\mathrm{NiO}, \mathrm{SnO}_{2}$, and $\mathrm{NiO}-\mathrm{SnO}_{2}$ thin films (Figure S2). A particulate film can be seen clearly in the case of ${ }_{200} \mathrm{NiO}-\mathrm{CNT}$ sample (Figure S2a). The power spectrum of the region encircled in the high-resolution transmission electron microscopy (HRTEM) image is typical of NiO (rock-salt, cubic) in [101] zone axis (Figure S2a-II). Figure S2b-d represent HRTEM images for the ${ }_{50} \mathrm{SnO}_{2}-\mathrm{CNT},{ }_{100} \mathrm{SnO}_{2}-\mathrm{CNT}$ and ${ }_{20} \mathrm{SnO}_{2}-\mathrm{CNT}$, respectively. The power spectra of the encircled regions shown in the HRTEM images of ${ }_{50} \mathrm{SnO}_{2}$-CNT (Figure S2b-II) and ${ }_{100} \mathrm{SnO}_{2}$-CNT (Figure S2c-II) are typical of $\mathrm{SnO}_{2}$ (cassiterite) in [100] and [111] zone axis, respectively. Figure S2e and f represent HRTEM micrographs for the ${ }_{200} \mathrm{NiO}-{ }_{50} \mathrm{SnO}_{2}-\mathrm{CNT}$ and ${ }_{350} \mathrm{NiO}-{ }_{50} \mathrm{SnO}_{2}-\mathrm{CNT}$ heterostructures, respectively, where the films composed of $\mathrm{NiO}$ and $\mathrm{SnO}_{2}$ can be identified as marked accordingly. The HRTEM and high-angle annular dark-field scanning transmission electron microscopy (HAADFSTEM) micrographs show a conformal and well-calibrated deposition of $\mathrm{NiO}, \mathrm{SnO}_{2}$ and $\mathrm{NiO}-\mathrm{SnO}_{2}$ and $\mathrm{SnO}_{2}-\mathrm{NiO}$ thin films onto the $\mathrm{CNT}$ substrate (Figure 1 and S2). The average thickness was estimated to ca. 6.3 and $9.5 \mathrm{~nm}$ for 200 and $350 \mathrm{NiO}-\mathrm{ALD}$ cycles, respectively. The average thickness was estimated to ca. 2.9, 8.5 and $17 \mathrm{~nm}$ for 20, 50 and $100 \mathrm{SnO}_{2}$-ALD cycles, respectively (Figure S2). Therefore, the thickness of both of the $\mathrm{SnO}_{2}$ and $\mathrm{NiO}$ films are well-controlled and increased linearly with increasing the number of ALD cycles, as expected for an ALD process. The energy-dispersive X-ray spectroscopy (EDX) elemental maps corresponding to the HAADF-STEM micrographs ${ }_{200} \mathrm{NiO}-\mathrm{CNT},{ }_{50} \mathrm{SnO}_{2}-\mathrm{CNT},{ }_{200} \mathrm{NiO}-{ }_{50} \mathrm{SnO}_{2}-\mathrm{CNT},{ }_{350} \mathrm{NiO}-{ }_{50} \mathrm{SnO}_{2}-\mathrm{CNT},{ }_{200} \mathrm{NiO}_{25} \mathrm{SnO}_{2}-$ $\mathrm{CNT}$ and ${ }_{50} \mathrm{SnO}_{2^{-2}{ }_{20}} \mathrm{NiO}-\mathrm{CNT}$ samples) further depict a homogeneous spatial distribution of all the respective elements in the metal oxides-shell and substrate, i.e. $\mathrm{Ni}, \mathrm{Sn}, \mathrm{O}$ and $\mathrm{C}$, in an orderly fashion confirming a well-defined core-shell hierarchical heterostructure (Figure 1a- f). The average thicknesses of the different coatings estimated from the EDX maps/BF-TEM images (marked as an example accordingly in Figure 1 and S2) and spectroscopic ellipsometry (SE) are presented in Table S1. X-ray photoelectron spectroscopy (XPS) core level spectra along with Auger spectra confirm the presence of hydroxylated surface region of $\mathrm{NiO}$, i.e. $\mathrm{Ni}(\mathrm{OH})_{2}$, in both of the NiO-terminated ${ }_{200} \mathrm{NiO}$ CNT and ${ }_{200} \mathrm{NiO}_{-50} \mathrm{SnO}_{2}-\mathrm{CNT}$ CSHS (Figure S4-8). ${ }^{[11]}$ After a mild sputtering, the presence of $\mathrm{NiO}$ is further confirmed (XPS core level and Auger spectra, Figure S5a,b and Figure S6a,b, Figure S7b,c, and Auger parameters analysis, Wagner plot, Figure S8a). It is demonstrated that the surface of the ALD-NiO is hydroxylated, while the bulk remains $\mathrm{NiO}$ (for a comprehensive discussion, please see the SI and our earlier reports). ${ }^{[6 a, 11-12]}$ XPS core level spectra along with Auger electron spectra confirm the presence of $\mathrm{SnO}_{2}$ in all of the ${ }_{50} \mathrm{SnO}_{2}-\mathrm{CNT},{ }_{50} \mathrm{SnO}_{2-200} \mathrm{NiO}-\mathrm{CNT}$ and ${ }_{200} \mathrm{NiO}-{ }_{50} \mathrm{SnO}_{2}-\mathrm{CNT}$ CSHS (XPS core level and Auger spectra, Figure S5c,d and Figure S7a,d,f, and Auger parameters 
analysis, Wagner plot, Figure S8b). The valence band spectra and the energy band diagrams are shown in Figure S9 and S10, respectively.

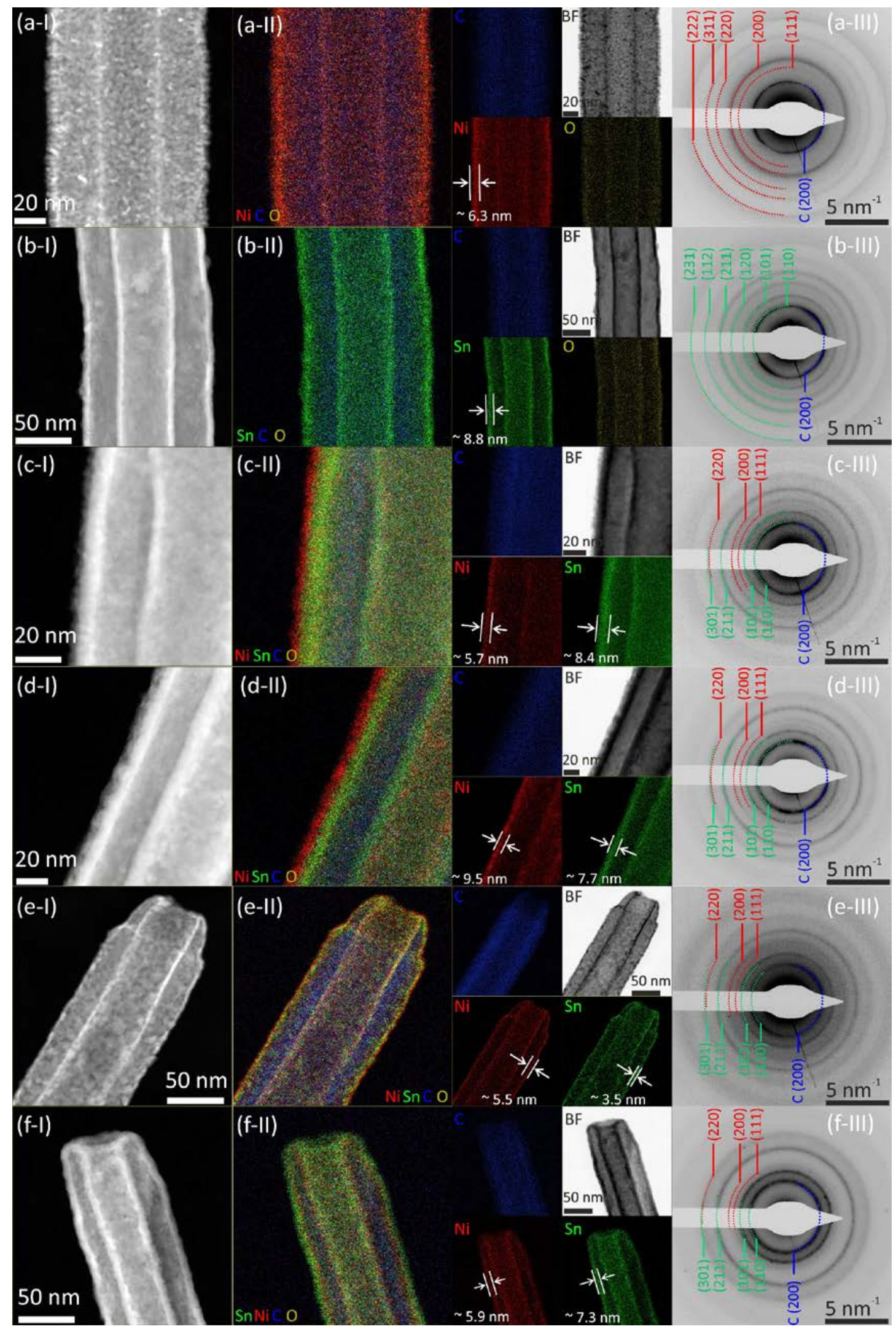

Figure 1. HAADF-STEM (I), corresponding EDX elemental maps (II) and SAED patterns (III) for (a) ${ }_{200} \mathrm{NiO}-\mathrm{CNT}$, (b) ${ }_{50} \mathrm{SnO}_{2}$-CNT, (c) ${ }_{200} \mathrm{NiO}-{ }_{50} \mathrm{SnO}_{2}-\mathrm{CNT}$, (d) ${ }_{350} \mathrm{NiO}-{ }_{50} \mathrm{SnO}_{2}-\mathrm{CNT}$, (e) ${ }_{200} \mathrm{NiO}_{25} \mathrm{SnO}_{2}-$ 


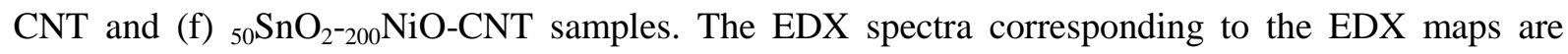
shown in Figure S3.

Figure 2a shows the electrical resistance of all of the sensors measured in the temperature range 50$200^{\circ} \mathrm{C}$. The resistance of all of the ${ }_{n, p} \mathrm{SMOX}^{-\mathrm{CNT}}$ and ${ }_{n, p} \mathrm{SMOX}_{n, p} \mathrm{SMOX}_{\mathrm{CNT}}$ sensors decreased with increasing the temperature, proving their semiconducting behaviour (Figure 2a). In addition, the baseline resistance $\left(\mathrm{R}_{\mathrm{a}}\right)$ strongly depends on the sample (Figure $\mathbf{2 b}$ and Figure S11). Pristine-CNTs show the lowest resistance (ca. $82 \Omega$ at $200{ }^{\circ} \mathrm{C}$ in dry air), the $\mathrm{SnO}_{2}$ and $\mathrm{NiO}$ coated CNT samples (n,pSMOX-CNT) show a higher baseline resistance confirming: i) the SMOX conformal and homogeneous coating, and ii) the formation of electrical contacts between the ${ }_{n, p}$ SMOX-shell and the CNT-core. ${ }^{[1 \mathrm{~g}, 4,13]}$ Moreover, the $\mathrm{NiO}-\mathrm{SnO}_{2}$-CNT and $\mathrm{SnO}_{2}$-NiO-CNT sensors show a higher baselineresistance as compared to $\mathrm{NiO}-\mathrm{CNT}$ and $\mathrm{SnO}_{2}$-CNT CSHS, respectively. This further confirms the formation of a $p$ - $n$ heterojunction between the $n$-core and the $p$-shell, or vice versa (Figure $\mathbf{2 b}$, and baseline resistance in nitrogen Figure S11). ${ }^{[1,3 b, 3,43]}$ The electrical resistance for all of the CSHS sensors was also recorded in nitrogen (Figure S11). The change in resistance in nitrogen is attributed to the electronic coupling between SMOX-SMOX. ${ }^{[13]}$ The resistances of the $\mathrm{NiO}-\mathrm{SnO}_{2}-\mathrm{CNT}$ and $\mathrm{SnO}_{2}$-NiO-CNT CSHS increase significantly as compared to the NiO-CNT or $\mathrm{SnO}_{2}-\mathrm{CNT}$ CSHS (Figure S11). This is attributed to an additional component of the resistance at the $\mathrm{NiO}-\mathrm{SnO}_{2}$ or $\mathrm{SnO}_{2}$ $\mathrm{NiO}$ interface ( $p$ - $n$ junction) due to the space charge region. ${ }^{[13]}$

In the ${ }_{n, p}$ SMOX-CNT system, because of the high conductivity of CNTs, it is expected that the electrical current will flow through the junction between the CNT-core and the ${ }_{n, p} \mathrm{SMOX}$-shell $\left(\mathrm{SnO}_{2}\right.$ or $\mathrm{NiO}$ ) ( $c f$. Figure 3a,c). Because the electrons are forced to cross the ${ }_{n, p} \mathrm{SMOX}$-shell while traversing from one ${ }_{n, p} \mathrm{SMOX}-\mathrm{CNT}$ element to the other, the electron conduction can be interpreted by a series of resistance elements, i.e. the SMOX ( $\left.\mathrm{R}_{\mathrm{SMOX}}\right)$, the junction between the SMOX and the CNT ( $\mathrm{R}_{\mathrm{SMOX}}$ ${ }_{\mathrm{CNT}}$ ), the carbon nanotubes $\left(\mathrm{R}_{\mathrm{CNT}}\right)$, and the SMOX(shell)-SMOX(shell) homojunction ( $\mathrm{R}_{\mathrm{SMOX} \text {-SMOX), }}$ Figure 3a,c. Therefore, the resistance of ${ }_{n, p} \mathrm{SMOX}-\mathrm{CNT}$ sensors is dominated by the most resistive SMOX shells and/or the heterojunction formed between SMOX-shells and the CNTs. Indeed the largest resistances should dominate in a system of resistive elements in series, as also confirmed by the increase of the resistance with increasing the thickness of the SMOX-shell in these ${ }_{n, p}$ SMOX-CNT systems. ${ }^{[6 a]}$

For ${ }_{n, p} \mathrm{SMOX}-{ }_{p, n} \mathrm{SMOX}-\mathrm{CNT}$ heterostructures (i.e. ${ }_{X} \mathrm{NiO}_{-} \mathrm{SnO}_{2}-\mathrm{CNT}$ and ${ }_{Y} \mathrm{SnO}_{2-}{ }^{-} \mathrm{NiO}-\mathrm{CNT}$ ), there are additional resistance elements, related to the interface between the two $p$ and $n$ SMOX films, to be considered. First of all, the additional resistance elements would cause an increase in the overall resistance of the system Figure 3b,d. Similar to the ${ }_{n, p}$ SMOX-CNT systems discussed above, the electrical current will have to pass through the junction between the CNT-core and the ${ }_{n, p}$ SMOX-shell $\left(\mathrm{SnO}_{2}\right.$ or $\left.\mathrm{NiO}\right)$ due to the high conductivity of the CNTs, Figure 3b,d. Additionally, because the electron need to cross the outer SMOX-shell and the interfacial SMOX-layer, the electron conduction can be modelled by a series of resistive elements, i.e. the ${ }_{n, p} \mathrm{SMOX}\left(\mathrm{R}_{\mathrm{SMOX}}\right)$, the junction between the ${ }_{n} \mathrm{SMOX}_{p} \mathrm{SMOX}\left(\mathrm{R}_{\mathrm{SMOX}-\mathrm{SMOX}}\right)$, the ${ }_{n, p} \mathrm{SMOX}\left(\mathrm{R}_{\mathrm{SMOX}}\right)$, the junction between the interfacial ${ }_{n, p} \mathrm{SMOX}$

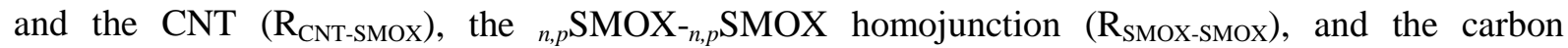
nanotubes $\left(\mathrm{R}_{\mathrm{CNT}}\right.$ ) ( $c$ f. Figure 3b,d). Thus, the resistance of the SMOX-SMOX-CNT sensors is dominated by the resistive SMOX-shell, homojunction between SMOX-shells (shell-shell), interfacialSMOX, the junction between SMOX-shell and interfacial-SMOX ( $p$ - $n$ interface). This implies that the overall dominating resistance may be provided by the two SMOXs and their interfaces. For example, the resistance of the ${ }_{n, p} \mathrm{SMOX}_{p, n} \mathrm{SMOX}-\mathrm{CNT}$ sensors increases with increasing the thickness of any of the components, as a matter of fact ${ }_{350} \mathrm{NiO}_{-50} \mathrm{SnO}_{2}$-CNT show a higher baseline resistance compared to the ${ }_{200} \mathrm{NiO}-{ }_{50} \mathrm{SnO}_{2}-\mathrm{CNT}$, and ${ }_{200} \mathrm{NiO}-{ }_{50} \mathrm{SnO}_{2}$-CNT CSHS show a higher baseline resistance compared to ${ }_{200} \mathrm{NiO}_{-25} \mathrm{SnO}_{2}-\mathrm{CNT}$ CSHS (cf. Figure $2 \mathbf{b}$ and Figure S11). 
The dynamic electrical response of all of the sensors was measured toward hydrogen in the temperature range $100-200^{\circ} \mathrm{C}$ (Figure S11). The isothermal response transients and the response of all the sensors at $200{ }^{\circ} \mathrm{C}$ (the optimal working temperature) is shown in Figure 2c,d. ${ }_{200} \mathrm{NiO}-\mathrm{CNT}$ and ${ }_{50} \mathrm{SnO}_{2}$-CNT CSHS show typical $p$ - and $n$-type sensing responses related to their intrinsic cations and anions deficiencies, respectively. ${ }^{[1 \mathrm{j}, 6 \mathrm{a}, 7,9 b, 14]}$ The thickness of the NiO-shell was fixed to $5.5-6.5 \mathrm{~nm}$ (200 ALD cycles) since it has been already optimized in our previous study. ${ }^{[6 a]}$ Noticeably, at this thickness which is similar to the Debye length, $\lambda_{\mathrm{D}}$, the whole layer participates in the resistance modulation and the sensing-response is maximized. ${ }^{[6 a]}$ The thickness of the $\mathrm{SnO}_{2}$ layer was fixed to 7.5-8.5 $\mathrm{nm}$ (50 ALD cycles) due to the optimized sensing response among the other tested sample (data not shown, $c f$. also below).

The NiO-CNT sensor shows a typical p-type response (3.2) toward 5000 ppm hydrogen. With the addition of $8.5 \mathrm{~nm} \mathrm{SnO}_{2}$ interfacial layer (sample ${ }_{200} \mathrm{NiO}_{-50} \mathrm{SnO}_{2}-\mathrm{CNT}$ ) the response decreases dramatically (1.1) and the response is reversed (Figure 2d). This change of response from $p$ - to $n$-type confirms that the overall response is not restricted to the NiO-shell, but is related to the $p$ - $n$ heterojunction formed between ${ }_{p} \mathrm{NiO}$ and ${ }_{n} \mathrm{SnO}_{2}$. Contrary to the NiO-CNT or $\mathrm{SnO}_{2}$-CNT systems, due to the similar band gap of $\mathrm{NiO}\left(3.6^{-4.2} \mathrm{eV}\right)^{[6 \mathrm{a}, 15]}$ and $\mathrm{SnO}_{2}(3.6 \mathrm{eV})^{[16]}$ and similar resistance $(c f$. Figure 2b) both of the SMOX layers in ${ }_{200} \mathrm{NiO}_{-50} \mathrm{SnO}_{2}-\mathrm{CNT}$ participate in the sensing response, i.e. to resistance modulation. In order to verify the role of the heterojunction in the sensing response in ${ }_{X} \mathrm{NiO}-$ ${ }_{\mathrm{Y}} \mathrm{SnO}_{2}$-CNT CSHS, two additional core-shell heterostructures are designed: ${ }_{200} \mathrm{NiO}_{25} \mathrm{SnO}_{2}-\mathrm{CNT}$ and ${ }_{350} \mathrm{NiO}-{ }_{50} \mathrm{SnO}_{2}$-CNT CSHS. In the first case $\left({ }_{200} \mathrm{NiO}_{-25} \mathrm{SnO}_{2}\right.$-CNT) the thickness of the interfacial $\mathrm{SnO}_{2}$ layer is decreased to $3.5 \mathrm{~nm}$ (25 ALD cycles); in the second case $\left({ }_{350} \mathrm{NiO}_{50} \mathrm{SnO}_{2}-\mathrm{CNT}\right)$, the thickness of the top NiO-shell increased to $9.5 \mathrm{~nm}$ (350 ALD cycles) while keeping the interfacial $\mathrm{SnO}_{2}$ thickness the same as for the reference sample $\left({ }_{200} \mathrm{NiO}_{50} \mathrm{SnO}_{2}-\mathrm{CNT}\right.$ sensor). Noticeably, the ${ }_{200} \mathrm{NiO}-$ ${ }_{25} \mathrm{SnO}_{2}$-CNT sensor shows a $p$-type response (1.1) (Figure 2d). Indeed, due to the very thin $\mathrm{SnO}_{2}$ film, fewer charge carriers are present and the layer is fully depleted. ${ }^{[6 a]} \mathrm{The}_{350} \mathrm{NiO}_{50} \mathrm{SnO}_{2}$-CNT sensor also show a $p$-type response (2.2) in contrast to the ${ }_{200} \mathrm{NiO}_{-50} \mathrm{SnO}_{2}-\mathrm{CNT}$ (Figure 2d). For a NiO-shell thickness larger than few times the $\lambda_{\mathrm{D}}$, ${ }^{[6]}$ because the $\mathrm{NiO}$ film does not participate fully in the modulation in resistance, the NiO-shell $\left(\mathrm{R}_{\mathrm{NiO}-\mathrm{NiO}}\right)$ dominates the sensing-response and the effect of the heterojunction becomes negligible (Figure $\mathbf{2 b}-\mathbf{d}$ ). On the other hand, for a NiO-shell thickness similar to the $\lambda_{\mathrm{D}}$, the response can be attributed to the heterojunction. The low sensing response is due to the fact that changes in surface resistance $\left(\mathrm{R}_{p s}\right)$ compensate for changes in the heterojunction resistance $\left(\mathrm{R}_{\mathrm{HJ}}\right), c f$. discussion of the Figure 5 below.

The ${ }_{50} \mathrm{SnO}_{2}$-CNT sensor shows a typical $n$-type sensing-response (1.7) towards $5000 \mathrm{ppm}$ of hydrogen. With the addition of an interfacial $\mathrm{NiO}$ layer $\left({ }_{50} \mathrm{SnO}_{2-200} \mathrm{NiO}-\mathrm{CNT}\right)$ the response towards hydrogen increases (5.3), Figure 2d. The increase in response of ${ }_{50} \mathrm{SnO}_{2-200} \mathrm{NiO}-\mathrm{CNT}$ sensor can be attributed to the formation of the $p-n$ heterojunction. It is likely that the NiO-core is completely in the spacecharge-region due to the heterojunction. Indeed, in the presence of a reducing gas, $\mathrm{SnO}_{2}$ accepts electrons and accordingly the surface resistance $\left(\mathrm{R}_{n s}\right)$ decreases. The effect of the modification in the surface resistance is extended to the heterojunction due to the fact that the thickness of $\mathrm{SnO}_{2}$, is comparable to the $\lambda_{\mathrm{D}}$. Therefore, changes in the surface resistance $\left(\mathrm{R}_{p s}\right)$ can be compensated by changes in the heterojunction resistance $\left(\mathrm{R}_{\mathrm{HJ}}\right)$. However, an increase in sensing response for ${ }_{50} \mathrm{SnO}_{2}-$ ${ }_{200} \mathrm{NiO}-\mathrm{CNT}$ sensor (as compared to the ${ }_{50} \mathrm{SnO}_{2}$-CNT sensor) is not yet fully understood. Most probably, due to the thin NiO-core, there are not enough charge carriers and the heterojunction is in a non-equilibrium state. The effect of the thickness of the NiO core needs to be analyzed further in a systematic way in order to gain a deeper insight. The preservation of the $n$-type response is probably due to the dominant response of $n$-type SMOX over $p$-type SMOX.$^{[3 b, 17]}$ This is confirmed by the observation that the sensing-response changed to $p$-type with the addition of a comparatively thick NiO-shell on top of the ${ }_{50} \mathrm{SnO}_{2}-\mathrm{CNT}\left({ }_{350} \mathrm{NiO}_{-50} \mathrm{SnO}_{2}-\mathrm{CNT}\right.$, Figure 2d), in this case the contribution of 
the NiO-shell becomes dominant due to the presence of a considerable bulk-like region in between the surface and heterojunction (Figure 2d).

Our results show that despite the electronic couplings and $p$ - $n$ heterojunctions in all of the ${ }_{p} \mathrm{SMOX}$ ${ }_{n} \mathrm{SMOX}-\mathrm{CNT}\left({ }_{X} \mathrm{NiO}-{ }_{Y} \mathrm{SnO}_{2}-\mathrm{CNT}\right)$ and ${ }_{n} \mathrm{SMOX}-{ }_{p} \mathrm{SMOX}-\mathrm{CNT}\left({ }_{Y} \mathrm{SnO}_{2-}{ }_{-} \mathrm{NiO}-\mathrm{CNT}\right) \mathrm{CSHS}$, the sensing response is not always governed by the semiconductor heterojunction. Indeed, one needs to keep in mind that the largest resistance element, when resistances are placed in series, plays the most important role in the effective conduction pathway and the overall resistance modulation (i.e., in the sensing response). Therefore, the transduction in these core-shell heterostructures can be described as follows:

- Due to the conformal SMOX coatings the current is forced to pass through the heterojunction and all the resistance elements are arranged in series as depicted in Figure 3. When a higher resistance element than the $\mathrm{R}_{\mathrm{SnO}_{2}-\mathrm{NiO}}$ or $\mathrm{R}_{\mathrm{NiO}-\mathrm{SnO}_{2}}$ (i.e. the ones related to the $n-p$ or $p-n$ heterojunction) is present in the system, the response may not be due to the heterojunction, but to the dominant resistance such as a more resistive shell layer ( $c f$. the case of ${ }_{350} \mathrm{NiO}-{ }_{50} \mathrm{SnO}_{2}$ in which the $\mathrm{NiO}$ shell exhibits a larger resistance).

- When the two SMOX have a comparable resistance and band gaps, the response can be governed by the $p-n$ heterojunction due to the significant contribution of the heterojunction resistance and its modulation by the reaction of the analyte with the shell material ( $c f$. the case of ${ }_{50} \mathrm{SnO}_{2^{-}{ }_{200}} \mathrm{NiO}$ and ${ }_{200} \mathrm{NiO}_{-50} \mathrm{SnO}_{2}-\mathrm{CNT}$ ). 

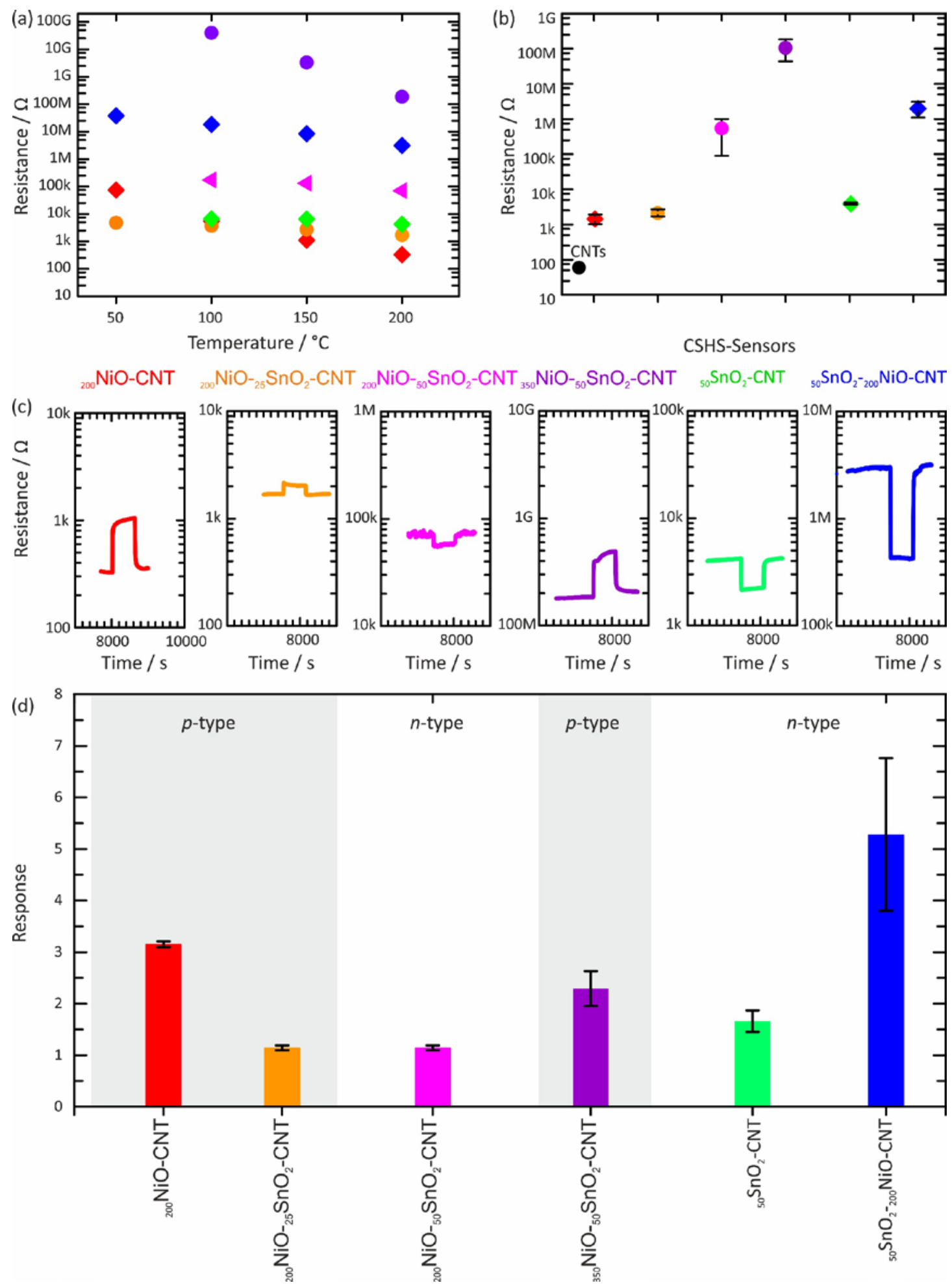

Figure 2. (a) The electrical resistance of $\mathrm{NiO}$ - and $\mathrm{SnO}_{2}$-coated CNT CSHS in dry air at temperatures ranges $50-200^{\circ} \mathrm{C}$. (b) The baseline resistance of the ${ }_{p, n} \mathrm{SMOX}-\mathrm{CNT},{ }_{p, n} \mathrm{SMOX}_{n, p} \mathrm{SMOX}$-CNT CSHS at $200^{\circ} \mathrm{C}$. Isothermal transient response curves of all of the fabricated sensors ( $p, n$ SMOX-CNT, ${ }_{p, n} \mathrm{SMOX}_{-, p} \mathrm{SMOX}-\mathrm{CNT} \mathrm{CSHS}$ ) at $200{ }^{\circ} \mathrm{C}$ toward $\mathrm{H}_{2}$ (5000 ppm) in dry air. (d) Gas sensing response of ${ }_{200} \mathrm{NiO}-\mathrm{CNT},{ }_{200} \mathrm{NiO}_{25} \mathrm{SnO}_{2}-\mathrm{CNT},{ }_{200} \mathrm{NiO}-{ }_{50} \mathrm{SnO}_{2}-\mathrm{CNT},{ }_{350} \mathrm{NiO}_{-50} \mathrm{SnO}_{2}-\mathrm{CNT},{ }_{50} \mathrm{SnO}_{2}-\mathrm{CNT}$, and ${ }_{50} \mathrm{SnO}_{2^{-}{ }_{200}} \mathrm{NiO}-\mathrm{CNT}$ CSHS sensors towards $\mathrm{H}_{2}(5000 \mathrm{ppm})$ at $200{ }^{\circ} \mathrm{C}$. The data presented in panels' b and $\mathrm{d}$ is the average of the duplicate measurements, where the error bars present the standard error. 

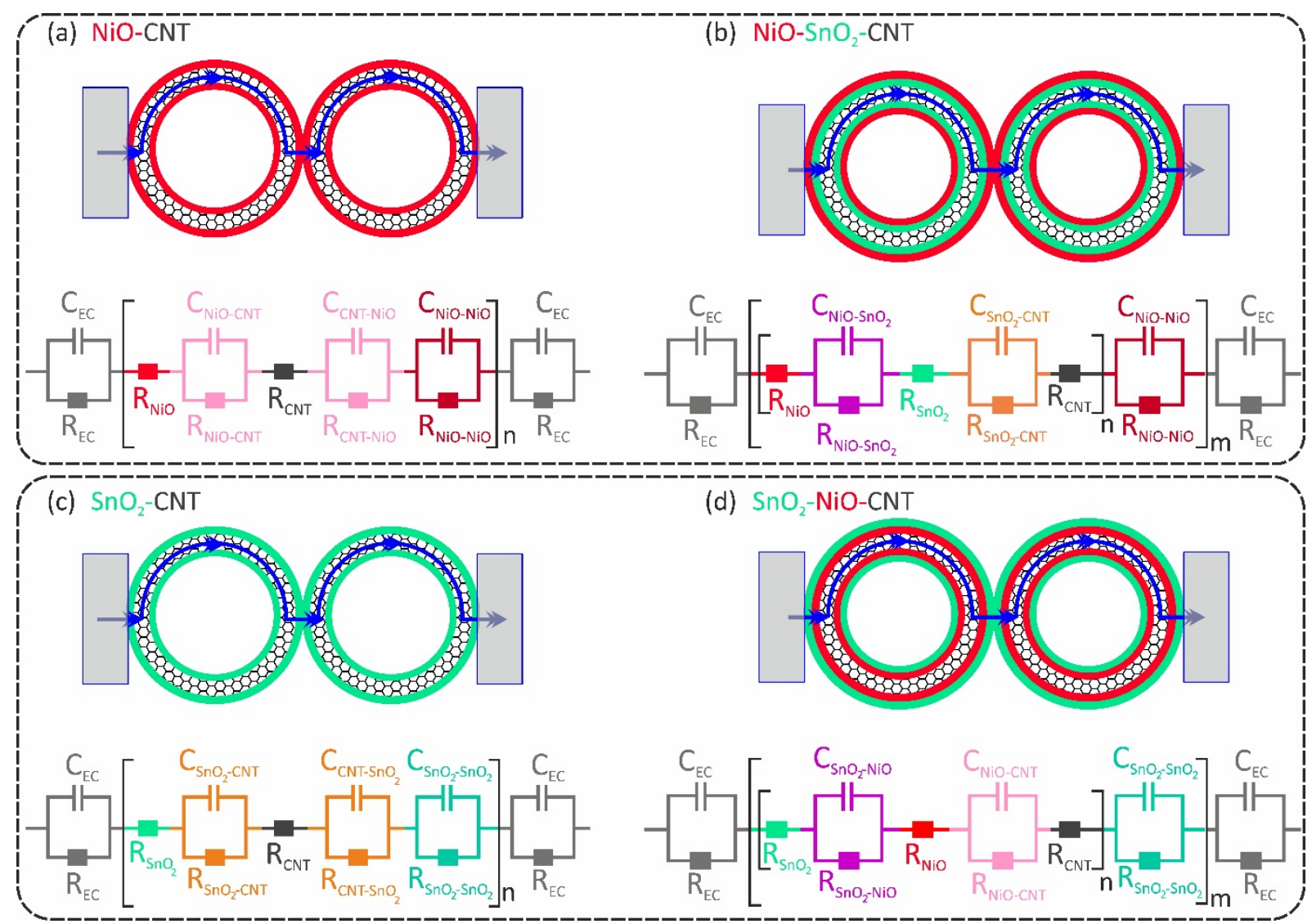

Figure 3. The schematic representation of the cross-section view and the corresponding equivalent circuits modelled for the sensors composed of: (a) NiO-CNT, (b) NiO-SnO $2-C N T$, (c) $\mathrm{SnO}_{2}-\mathrm{CNT}$ and (d) $\mathrm{SnO}_{2}$-NiO-CNT CSHS. The charge transfer is presented by a series of the two electrode contacts (glossy-grey), which are determined by the difference in the work function of the two materials, and two parallel resistors. The corresponding proposed equivalent circuits are presented by a series of bulk and interface resistances, where the interface resistance is composed of a parallel connection of the corresponding resistance (R) and capacitance at the interface (C). The interface resistance of the electrode-semiconductor can be ignored as compared to the resistance elements within the heterostructures, e,g., the $p-n$ interface, the resistance of the shell, resistance of shell-shell homojunction. The cited references are recommended for a further detail. ${ }^{[3 b, 17]}$

In light of the above results involving core-shell heterostructures, here we present a general overview about the change in work functions and serial resistances, and their ultimate impacts on the gas sensing properties. Figure 4a,b shows the qualitative energy band diagrams for $p-n$ and $n-p$ heterojunction, where the thicknesses of both of the ${ }_{p} \mathrm{SMOX}$ and ${ }_{n} \mathrm{SMOX}$ are greater than their respective Debye lengths $\left(\lambda_{\mathrm{D}}\right)$. The following main resistive elements are arranged in series: (i) resistance of the depletion region at the surface, $\mathrm{R}_{n s}$ or $\mathrm{R}_{p s}$, i.e., hole-accumulation layer (HAL) or electron-depletion layer (EDL) in case of $p$ - and $n$-SMOX at the top faces the atmosphere, respectively, (ii) the resistance of the space charge region at the $p$ - $n$ or $n$ - $p$ heterojunctions $\left(\mathrm{R}_{\mathrm{HJ}}\right)$, and (iii) in between the $\mathrm{R}_{\mathrm{HJ}}$ and $\mathrm{R}_{p s}$ or $\mathrm{R}_{n s}$, a resistive element consisting of the bulk of the respective SMOX (i.e., resistance of the bulk of the $n$ - $\left(\mathrm{R}_{n \mathrm{~b}}\right)$ or $p$-SMOX $\left(\mathrm{R}_{p \mathrm{~b}}\right)$ as shown in Figure $4 \mathbf{a}, \mathbf{b}$. The difference of the concentrations of charges on both sides decide how extended is the heterojunction, i.e., the width of the space-charge-region. For example, more charge carriers on $n$-side are likely to promote the transfer of more electrons to the $p$-type side of the heterojunction, and the space-charge-region will be extended more into the $p$-type SMOX. Importantly, $\mathrm{R}_{p s}$ and $\mathrm{R}_{n s}$ are the resistances that can be directly influenced due to the surface interaction with the analytes, whereas the change in $\mathrm{R}_{\mathrm{HJ}}$ depends 
upon the bulk element, more precisely, the thickness of the coating. It is likely that the changes going on at the surface will be minimally impacted if there is a substantial distance between the heterojunction and the surface-charge-region. Overall, in these resistances in series, the resistance element(s) with a relatively larger modulation dominates in the overall sensing-response, and that should be the resistance at the surface, e.g, the case of ${ }_{350} \mathrm{NiO}_{-50} \mathrm{SnO}_{2}-\mathrm{CNT}$ sensor.
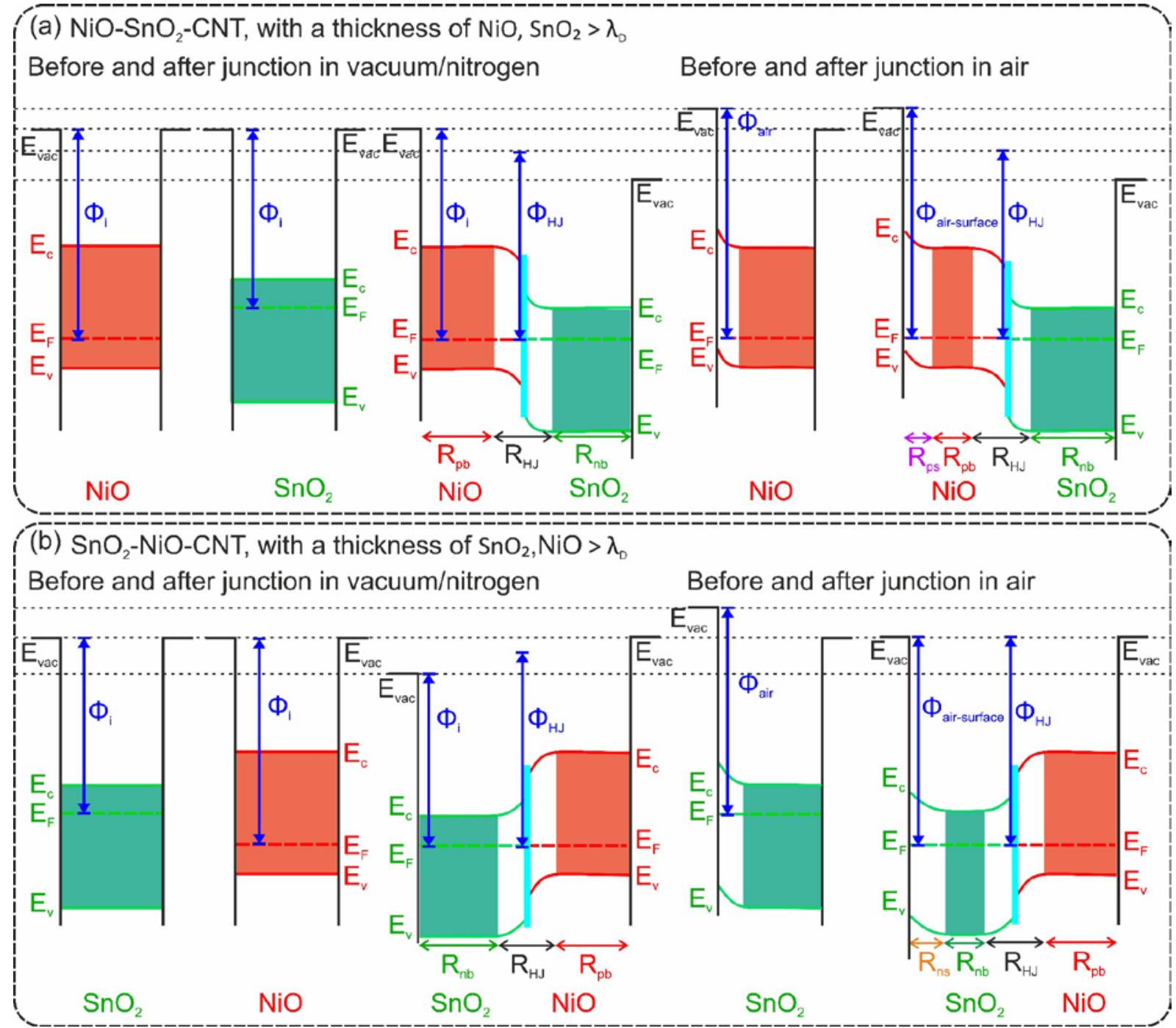

Figure 4. Energy bands representation of (a) $\mathrm{NiO}-\mathrm{SnO}_{2}-\mathrm{CNT}$ and (b) $\mathrm{SnO}_{2}-\mathrm{NiO}-\mathrm{CNT}$ CSHS, where the thickness of both of the $\mathrm{NiO}$ and $\mathrm{SnO}_{2}$ are greater than the respective Debye lengths (i.e., thickness $>\lambda_{\mathrm{D}}$ ). The Figures showing different contributions to the work function before heterojunction and after heterojunction in vacuum/nitrogen, and in air. Band gaps for both of the $\mathrm{SnO}_{2}$ and $\mathrm{NiO}$ is considered similar as reported in the literature, i.e., $\mathrm{NiO}(3.6 \mathrm{eV})^{[6 a, 15]}$ and $\mathrm{SnO}_{2}(3.6 \mathrm{eV}) \cdot{ }^{[16]}$ The symbols used for the different parameters are: $E_{\mathrm{Vac}}$ vacuum level; $\mathrm{E}_{\mathrm{C}}$, conduction band; $\mathrm{E}_{\mathrm{v}}$, valence band; $\mathrm{E}_{\mathrm{F}}$, Fermi level; $\mathrm{R}_{n \mathrm{~b}}$, resistance of ${ }_{n} \mathrm{SMOX}$ (bulk); $\mathrm{R}_{p \mathrm{~b}}$, resistance of ${ }_{p} \mathrm{SMOX}$ (bulk); $\mathrm{R}_{\mathrm{HJ}}$, resistance at $p$ - $n$ heterojunction; $\mathrm{R}_{n s}$, resistance of ${ }_{n} \mathrm{SMOX}$ (surface); $\mathrm{R}_{p s}$, resistance of ${ }_{p} \mathrm{SMOX}$ (surface); $\Phi_{\mathrm{i}}$, work function in vacuum/nitrogen; $\Phi_{\text {air }}$, work function in air; $\Phi_{\mathrm{HJ}}$, work function at $p-n$ heterojunction. (a): $\Phi_{\text {i-vacuum/nitrogen }}(\mathrm{NiO})<\Phi_{\text {i-air }}(\mathrm{NiO}), \Phi_{\text {i-vacuum/nitrogen }}(\mathrm{NiO})>\Phi_{\mathrm{HJ}-\text { vacuum/nitrogen, }}, \Phi_{\text {air-surface }}$ $(\mathrm{NiO})>\Phi_{\mathrm{HJ} \text {-air }} \sim \Phi_{\text {i-vacuum/nitrogen-bulk }}(\mathrm{NiO}), \mathrm{R}_{p s-\text { air }}(\mathrm{NiO})<\mathrm{R}_{\mathrm{HJ}}$. (b) $\Phi_{\text {i-vacuum/nitrogen }}\left(\mathrm{SnO}_{2}\right)<\Phi_{\text {i-air }}\left(\mathrm{SnO}_{2}\right)$, $\Phi_{\text {i-vacuum/nitrogen }}\left(\mathrm{SnO}_{2}\right)<\Phi_{\mathrm{HJ} \text {-vacuum/nitrogen }}\left(\mathrm{SnO}_{2}\right), \Phi_{\text {i-air }}\left(\mathrm{SnO}_{2}\right) \sim \Phi_{\mathrm{HJ} \text {-air }} \sim \Phi_{\text {i-vacuum/nitrogen-bulk }}\left(\mathrm{SnO}_{2}\right), \mathrm{R}_{\text {ns-air }}$ $\left(\mathrm{SnO}_{2}\right)<\mathrm{R}_{\mathrm{HJ}}$. 
On the other hand, Figure 5a,b shows the energy band diagram for the $p$ - $n$ type heterojunction (e.g., $\mathrm{NiO}-\mathrm{SnO}_{2}$-CNT) with a thickness ${ }_{p} \mathrm{SMOX} \leq \lambda_{\mathrm{D}}$ and ${ }_{n} \mathrm{SMOX}>\lambda_{\mathrm{D}}$, and an $n-p$ type heterojunction (e.g., $\mathrm{SnO}_{2}$-NiO-CNT) with a thickness ${ }_{n} \mathrm{SMOX} \leq \lambda_{\mathrm{D}}$ and ${ }_{p} \mathrm{SMOX}>\lambda_{\mathrm{D}}$, respectively. As the materials faces the atmosphere, i.e. the top-most layer is thin enough to be comparable to the Debye length of the materials, whether it is ${ }_{n} \mathrm{SMOX}\left(\mathrm{SnO}_{2}\right)$ or ${ }_{p} \mathrm{SMOX}(\mathrm{NiO})$; the whole material would be in the space charge region. There would be the arrangement of resistive elements without a considerable bulk contribution of the topmost layer, such as $\mathrm{R}_{n s}$ or $\mathrm{R}_{p s}$ are directly linked to the $\mathrm{R}_{\mathrm{HJ}}$. In this case, any change in the resistance of the surface region would most likely be extended directly into the heterojunction, and the heterojunction would play an important role in influencing the sensor response by either decreasing or increasing it. In the case of the ${ }_{200} \mathrm{NiO}_{-50} \mathrm{SnO}_{2}-\mathrm{CNT}$ sensor, the response toward $\mathrm{H}_{2}$ decreases because the change in the surface resistance $\left(\mathrm{R}_{p s}\right)$ compensates for the change in the resistance at the heterojunction $\left(\mathrm{R}_{\mathrm{HJ}}\right)$. On the other hand, the ${ }_{50} \mathrm{SnO}_{2-200} \mathrm{NiO}-\mathrm{CNT}$ sensor exhibits a higher response.
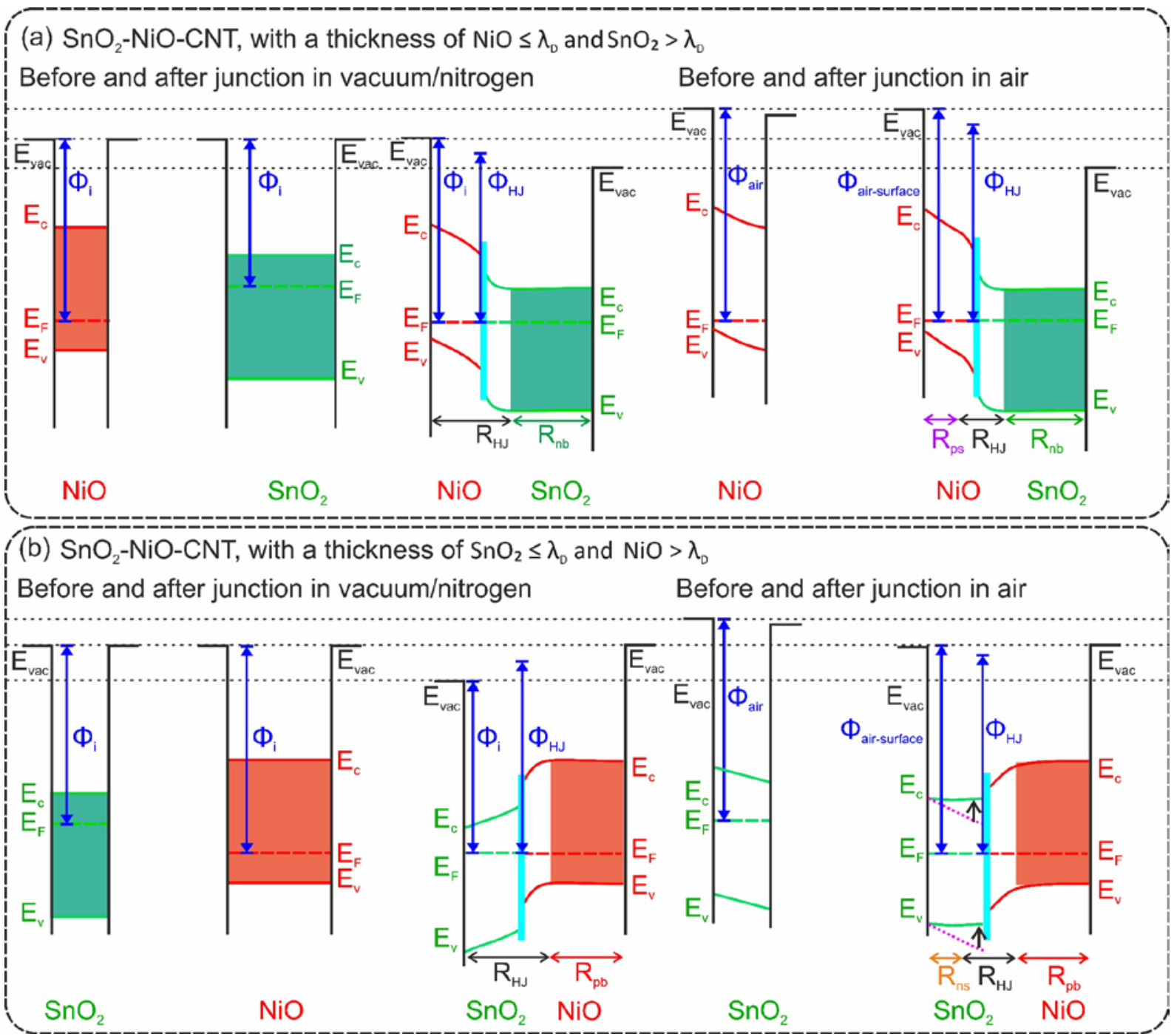

Figure 5. Energy bands representation of (a) $\mathrm{NiO}-\mathrm{SnO}_{2}-\mathrm{CNT}$ and (b) $\mathrm{SnO}_{2}-\mathrm{NiO}-\mathrm{CNT} \mathrm{CSHS}$, in the case where the $\mathrm{NiO}$ and $\mathrm{SnO}_{2}$ shell layers are of similar thickness to their Debye lengths (i.e., thickness $\leq \lambda_{\mathrm{D}}$ ), and the thickness of the cores of $\mathrm{NiO}$ and $\mathrm{SnO}_{2}$ are greater than the $\lambda_{\mathrm{D}}$. The Figures showing different contributions to the work function and resistances before heterojunction and after heterojunction in vacuum/nitrogen and in air. (a): $\Phi_{\text {i-vacuum }}(\mathrm{NiO})<\Phi_{\text {i-air }}(\mathrm{NiO}), \Phi_{\text {surface-vacuum/nitrogen }}(\mathrm{NiO})$ $>\Phi_{\mathrm{HJ}-\text { vacuum/nitrogen }}(\mathrm{NiO}), \Phi_{\text {surface-air }}(\mathrm{NiO})>\Phi_{\mathrm{HJ} \text {-air }}(\mathrm{NiO}) \geq \Phi_{\text {i-air }}(\mathrm{NiO}), \mathrm{R}_{\mathrm{ps}-\text { air }}<\mathrm{R}_{\mathrm{HJ}}$. $(\mathrm{b}) \Phi_{\text {i-vacuum }}\left(\mathrm{SnO}_{2}\right)<$ 
$\Phi_{\text {i-air }}\left(\mathrm{SnO}_{2}\right), \Phi_{\text {surface-vacuum/nitrogen }}\left(\mathrm{SnO}_{2}\right)<\Phi_{\mathrm{HJ} \text {-vacuum/nitrogen }}\left(\mathrm{SnO}_{2}\right), \Phi_{\text {surface-air }}\left(\mathrm{SnO}_{2}\right)<\Phi_{\mathrm{HJ}-\text { air }}<\Phi_{\text {i-air }}$ $\left(\mathrm{SnO}_{2}\right), \mathrm{R}_{\mathrm{ns}-\mathrm{air}} \sim \mathrm{R}_{\mathrm{HJ}}$.

In summary, in the case of a shell layer thicker than the Debye length, the heterojunction parameters are not modified. Therefore, the response of the sensor will be solely governed by the resistance change at the surface of the material facing the atmosphere. Only in the case in which the changes at the surface are extended into the whole heterostructure (i.e. shell thickness $\leq \lambda_{\mathrm{D}}$ ), the heterojunction can play an important role on the sensor response, both in terms of a decrease or an increase of the response. Despite the fact that the response in this case is related to the heterojunction, it does not always lead to an increase of the sensing response. Indeed, the role of heterojunction is extremely sensitive to the thickness of both the shell and the core material.

In our study a comprehensive understanding of the role of semiconductor heterojunctions and of the sensing response of core-shell heterostructures is achieved by synthesizing a series of logically designed, well-defined, and well-controlled heterostructures with different thicknesses of the core and shell layers. Prototypes ${ }_{n} \mathrm{SMOX}-\mathrm{CNT},{ }_{p} \mathrm{SMOX}-\mathrm{CNT},{ }_{p} \mathrm{SMOX}{ }_{n} \mathrm{SMOX}-\mathrm{CNT}$, and ${ }_{n} \mathrm{SMOX}-{ }_{p} \mathrm{SMOX}-$ CNT hierarchical coaxial core-shell heterostructures are therefore been proposed to achieve this objective. The sensing-response was found to be restricted to the SMOX-shell layer in the ${ }_{n, p}$ SMOXCNT core-shell heterostructures. On the other hand, ${ }_{p, n} \mathrm{SMOX}_{n, p} \mathrm{SMOX}-\mathrm{CNT}$ core-shell heterostructures with thickness of the SMOX-shell and the interfacial-SMOX in a well-defined range showed for the first time a response that can be directly and unambiguously related to the $p-n$ heterojunction. In this case, the changes at the surface extend into the heterojunction. All in all, we can anticipate that the elucidation of the role of $p$ - $n$ heterojunctions in semiconducting metal oxides-based gas sensors will permit to develop a novel generation of devices in which the heterojunction will play a primordial role.

\section{Acknowledgments}

We thankfully acknowledged Christoph Erdmann for TEM measurements. 


\section{References}

[1] a) E. Comini, Materials Today Advances 2020, 7, 100099; b) N. Kaur, M. Singh and E. Comini, Langmuir 2020, 36, 6326-6344; c) J. Zhang and X. Liu in One-Dimensional Nanowire-Based Heterostructures for Gas Sensors, Eds.: G. Shen and Y.-L. Chueh), Springer Singapore, Singapore, 2019, pp. 201-235; d) R. Malik, V. K. Tomer, Y. K. Mishra and L. Lin, Appl. Phys. Rev. 2020, 7 , 021301; e) D. R. Miller, S. A. Akbar and P. A. Morris, Sens. Actuators, B 2014, 204, 250-272; f) J. Kong, N. R. Franklin, C. Zhou, M. G. Chapline, S. Peng, K. Cho and H. Dai, Science 2000, 287, 622; g) F. Li, X. Gao, R. Wang, T. Zhang, G. Lu and N. Barsan, ACS Appl. Mater. Interfaces 2016, 8, 19799-19806; h) N. Pinna, G. Neri, M. Antonietti and M. Niederberger, Angew. Chem. Int. Ed. 2004, 43, 4345-4349; i) P. A. Russo, N. Donato, S. G. Leonardi, S. Baek, D. E. Conte, G. Neri and N. Pinna, Angew. Chem. Int. Ed. 2012, 51, 11053-11057; j) M. H. Raza, N. Kaur, E. Comini and N. Pinna, ACS Appl. Mater. Interfaces 2020, 12, 4594-4606.

[2] Y. Jian, W. Hu, Z. Zhao, P. Cheng, H. Haick, M. Yao and W. Wu, Nano-Micro Letters 2020, 12, 71.

[3] a) P. Karnati, S. Akbar and P. A. Morris, Sens. Actuators, B 2019, 295, 127-143; b) D. Degler, U. Weimar and N. Barsan, ACS Sens. 2019, 4, 2228-2249; c) A.-K. Elger and C. Hess, Angew. Chem. Int. Ed. 2019, 58, 15057-15061; d) N. Yamazoe and K. Shimanoe, Sens. Actuators, B 2011, 160, $1352-$ 1362.

[4] A. Staerz, X. Gao, F. Cetmi, Z. Ming, U. Weimar, T. Zhang and N. Barsan, ACS Appl. Mater. Interfaces 2020, 12, 21127-21132.

[5] a) J. M. Walker, S. A. Akbar and P. A. Morris, Sens. Actuators, B 2019, 286, 624-640; b) C. Marichy, P. A. Russo, M. Latino, J.-P. Tessonnier, M.-G. Willinger, N. Donato, G. Neri and N. Pinna, J. Phys. Chem. C 2013, 117, 19729-19739.

[6] a) M. H. Raza, K. Movlaee, S. G. Leonardi, N. Barsan, G. Neri and N. Pinna, Adv. Funct. Mater. 2020, 30, 1906874; b) J.-H. Lee, A. Katoch, S.-W. Choi, J.-H. Kim, H. W. Kim and S. S. Kim, ACS Appl. Mater. Interfaces 2015, 7, 3101-3109.

[7] M. H. Raza, N. Kaur, E. Comini and N. Pinna, Adv. Mater. Interfaces 2021, n/a, 2100939.

[8] E. Comini, Anal. Chim. Acta 2006, 568, 28-40.

[9] a) H.-R. Kim, A. Haensch, I.-D. Kim, N. Barsan, U. Weimar and J.-H. Lee, Adv. Funct. Mater. 2011, 21, 4402-4402; b) A. Staerz, T. Suzuki, U. Weimar and N. Barsan in 12 - SnO2: The most important base material for semiconducting metal oxide-based materials, (Ed. M. O. Orlandi), Elsevier, 2020, pp. 345-377.

[10] a) C. Marichy and N. Pinna, Adv. Mater. Interfaces 2016, 3, 1600335; b) C. Marichy and N. Pinna, Coord. Chem. Rev. 2013, 257, 3232-3253; c) C. Marichy, M. Bechelany and N. Pinna, Adv. Mater. 2012, 24, 1017-1032; d) A. P. C. Marichy, M. G. Willinger, N. Pinna in Coating of Carbon Nanotubes., (Ed. N. Pinna, Knez, M.), Wiley-VCH, 2012; e) M. H. Raza, K. Movlaee, Y. Wu, S. M. El-Refaei, M. Karg, S. G. Leonardi, G. Neri and N. Pinna, ChemElectroChem 2019, 6, 383-392.

[11] M. T. Greiner, M. G. Helander, Z.-B. Wang, W.-M. Tang and Z.-H. Lu, J. Phys. Chem. C 2010, 114, 19777-19781.

[12] Y. Fan, Y. Wu, G. Clavel, M. H. Raza, P. Amsalem, N. Koch and N. Pinna, ACS Appl. Energy Mater. 2018, 1, 4554-4563.

[13] a) A. Staerz, Y. Liu, U. Geyik, H. Brinkmann, U. Weimar, T. Zhang and N. Barsan, Sens. Actuators, B 2019, 291, 378-384; b) A. Staerz, T.-H. Kim, J.-H. Lee, U. Weimar and N. Barsan, J. Phys. Chem. C 2017, 121, 24701-24706.

[14] a) Q. Zhou, C. Tang, S. P. Zhu and W. G. Chen, Materials Technology 2015, 30, 349-355; b) L. $\mathrm{Xu}, \mathrm{R}$. Zheng, S. Liu, J. Song, J. Chen, B. Dong and H. Song, Inorg. Chem. 2012, 51, 7733-7740.

[15] J. Zhang, D. Zeng, Q. Zhu, J. Wu, Q. Huang, W. Zhang and C. Xie, PCCP 2016, 18, 5386-5396.

[16] H.-C. Chiu and C.-S. Yeh, J. Phys. Chem. C 2007, 111, 7256-7259.

[17] N. Barsan and U. Weimar, J. Electroceram. 2001, 7, 143-167. 


\section{Supporting Information}

\section{On the Role of Heterojunctions of Core-shell Heterostructures in Gas Sensing}

Muhammad Hamid Raza ${ }^{1}$, Roberto Di Chio ${ }^{2}$, Kaveh Movlaee², Patrick Amsalem ${ }^{3}$, Norbert Koch ${ }^{3,4}$, Nicolae Barsan ${ }^{5}$, Giovanni Neri ${ }^{2}$, Nicola Pinna ${ }^{1 *}$

1 -Institut für Chemie and IRIS Adlershof, Humboldt-Universität zu Berlin, Brook-Taylor-Str. 2, 12489 Berlin, Germany

2 -Department of Engineering, University of Messina, C.Da Di Dio, I-98166 Messina, Italy

3 -Institut für Physik and IRIS Adlershof, Humboldt-Universität zu Berlin, Brook-Taylor-Str. 2, 12489

Berlin, Germany

4 -Helmholtz-Zentrum Berlin GmbH, Albert-Einstein-Str. 15, 12489 Berlin, Germany

5 - Institute of Physical and Theoretical Chemistry, University of Tübingen, Auf der Morgenstelle 15, 72076 Tübingen, Germany

* Corresponding Author E-mail: nicola.pinna@hu-berlin.de 


\section{Contents}

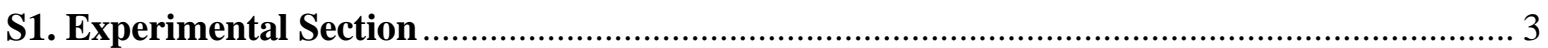

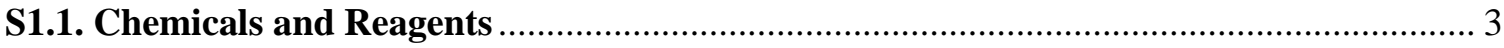

S1.2. Synthesis of NiO-CNT, $\mathrm{SnO}_{2}-\mathrm{CNT}, \mathrm{NiO}_{-} \mathrm{SnO}_{2}-\mathrm{CNT}$ and $\mathrm{SnO}_{2}$-NiO-CNT

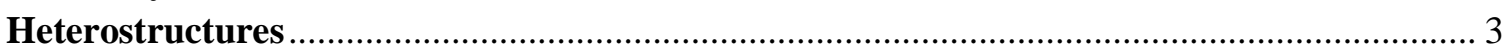

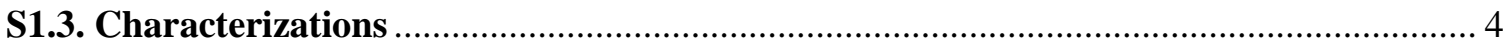

S1.4. Device Fabrication and Sensing Measurements ......................................................... 4

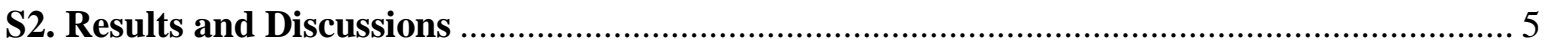

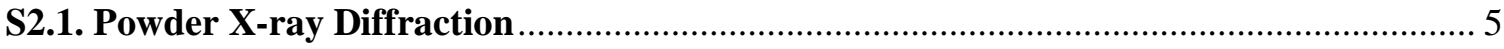

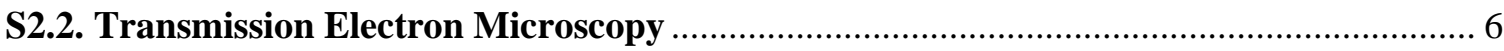

S2.3. X-ray and ultraviolet photoelectron spectroscopy ….................................................... 8

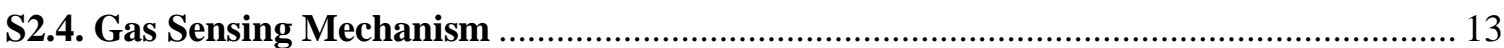

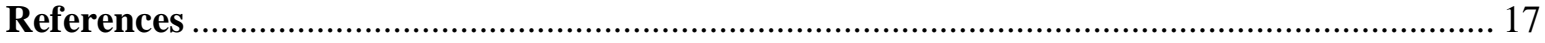




\section{S1. Experimental Section}

\section{S1.1. Chemicals and Reagents}

Carbon nanotubes, CNTs (PR24-PS, pyrograf III), and nitric acid (67\%) were provided by Applied Science, Inc., and VWR chemicals, respectively. Bis(cyclopentadienyl)nickel (Nickelocene, $\mathrm{Ni}(\mathrm{Cp})_{2}$, 99\%) was purchased from Strem Chemicals, Inc. Tetrakis(dimethylamido)tin(IV) (TDMASn, $\left.\left[\left(\mathrm{CH}_{3}\right)_{2} \mathrm{~N}\right]_{4} \mathrm{Sn}, 99.9 \%\right)$ was purchased from Merck KGaA. Ozone was used as produced using pure oxygen $(99.99 \%)$ at 0.5 bar in a BMT803N ozone generator. Argon, nitrogen and oxygen were supplied by Air Liquide (99.99\% purity). Other tests gases used in the gas-sensing tests such as $\mathrm{H}_{2}$ were supplied from certified bottles purchased from SOL Group, Italy. All other chemicals and reagents were of analytical grades and used without further purification unless otherwise stated.

\section{S1.2. Synthesis of NiO-CNT, $\mathrm{SnO}_{2}-\mathrm{CNT}$, NiO-SnO ${ }_{2}-\mathrm{CNT}$ and $\mathrm{SnO}_{2}-\mathrm{NiO}-\mathrm{CNT}$ Heterostructures}

\section{S1.2.1. Functionalization of Carbon Nanotubes}

First of all, as-purchased carbon nanotubes were treated with nitric acid $\left(\mathrm{HNO}_{3}, 67 \%\right)$ at $105{ }^{\circ} \mathrm{C}$ under reflux for $6 \mathrm{~h}^{[1]}$ After that, the mixture was washed and filtered multiple times using deionized water until the $\mathrm{pH}=7$. The oxidized CNTs were collected and dried in oven at $80^{\circ} \mathrm{C}$ for overnight. This type of treatment of CNTs with nitric acid allows the generation of oxygenated functional groups that later act as nucleation sites for the chemisorption of the metal precursors enabling the growth of conformal and homogeneous film by ALD. ${ }^{[2]}$ In fact, the initiation of film growth onto the CNTs requires the presence of functional surface groups or defect sites that act as anchoring and nucleation sites. ${ }^{[2 a]}$

\section{S1.2.2. Atomic Layer Deposition (ALD)}

The semiconducting metal oxides (SMOX) films, i.e. $\mathrm{NiO}$ and $\mathrm{SnO}_{2}$, were deposited onto the oxidized CNTs by ALD using a commercial thermal ALD system by ARRADIANCE, Inc. (GEMSTAR-6). The ALD system was evacuated and the temperature of the chamber and manifolds was stabilized before proceeding to ALD process. The baseline pressure was maintained at approx. $8.5 \cdot 10^{-2}$ mbar with a $10 \mathrm{sccm}$ of argon mass flow. Si-wafers (Siegert wafer B014002, Single side polished) were cleaned in Piranha solution, ethanol, isopropanol, and deionized water followed with nitrogen blow drying. These Si-wafers with a natural $\mathrm{SiO}_{2}$ layer (ca. $1.2-1.8 \mathrm{~nm}$ ) were also put into the ALD chamber along with the CNTs samples to calibrate the $\mathrm{SnO}_{2}$ and $\mathrm{NiO}$ thicknesses by spectroscopic ellipsometry (SE). All of the samples were in-situ cleaned using ozone (total exposure time as $200 \mathrm{~s}$ ) before starting ALD process.

\section{S1.2.2.1. Atomic Layer Deposition of $\mathrm{SnO}_{2}$}

Atomic layer deposition of $\mathrm{SnO}_{2}$ was performed using Tetrakis(dimethylamido)tin(IV), TDMASn, and ozone as metal precursor and a source of oxygen, respectively. TDMASn was maintained in a stainless steel container at $50{ }^{\circ} \mathrm{C}$, while ozone (approx. $70-90 \mathrm{~g} / \mathrm{Nm}^{3}$ ) was introduced as generated at RT. The TDMASn and ozone were supplied using two separate manifolds which were maintained at 120 and $100{ }^{\circ} \mathrm{C}$, respectively. The temperature of the reaction chamber was maintained at $190{ }^{\circ} \mathrm{C}$. Argon was used as carrier and purging gas to carry the precursors into the reaction chamber and to remove any of the excess reagents and reaction by-products, respectively. Both of the precursors were introduced in a sequential manner of pulse/exposure/purge, whereas one ALD cycles was adjusted as $0.5 \mathrm{~s} / 30 \mathrm{~s} / 20 \mathrm{~s}$ and $0.2 \mathrm{~s} / 20 \mathrm{~s} / 30 \mathrm{~s}$ for TDMASn and ozone, respectively. After the $\mathrm{SnO}_{2}$ ALD process, all of the samples were in-situ annealed at $300^{\circ} \mathrm{C}$ for 5 hours using oxygen pulses $(0.2 \mathrm{~s}$ pulse/300 s exposure/60 s argon purge). 


\section{S1.2.2.2. Atomic Layer Deposition of NiO}

Atomic layer deposition of $\mathrm{NiO}$ was performed using Bis(cyclopentadienyl)nickel, nickelocene and ozone as metal precursor and oxygen source, respectively. The temperature of the $\mathrm{Ni}(\mathrm{Cp})_{2}$ container and the reaction chamber was maintained at 90 and $200{ }^{\circ} \mathrm{C}$, respectively. Keeping in view the low vapour pressure of nickelocene, an additional argon booster was applied as pulsed-vapor-push technique $\left(\mathrm{PVP}^{\mathrm{TM}}\right)$ to boost the nickelocene vapors into the reaction chamber. The pulsing/exposure/purge time for nickelocene and ozone was adjusted to $1.2 \mathrm{~s} / 30 \mathrm{~s} / 30 \mathrm{~s}$ and $0.2 \mathrm{~s} / 30 \mathrm{~s} / 30 \mathrm{~s}$, respectively. All of the rest parameters and ALD conditions were kept same as described above for the $\mathrm{SnO}_{2} \mathrm{ALD}$.

The thicknesses of the $\mathrm{NiO}$ and $\mathrm{SnO}_{2}$ deposited layers were controlled by varying the number of ALD cycles as 200-350 and 20-100 ALD, respectively. A series of samples was synthesized composed of any of the $\mathrm{NiO}\left({ }_{p} \mathrm{SMOX}\right)$ or $\mathrm{SnO}_{2}\left({ }_{n} \mathrm{SMOX}\right)$, i.e., ${ }_{X} \mathrm{NiO}-\mathrm{CNT}$ and ${ }_{Y} \mathrm{SnO}_{2}-\mathrm{CNT}$, and two types of ${ }_{n, p} \mathrm{SMOX}$-shells $\left({ }_{X} \mathrm{NiO}-{ }_{Y} \mathrm{SnO}_{2}-\mathrm{CNT}\right.$ and $\left.{ }_{Y} \mathrm{SnO}_{2-}{ }_{-} \mathrm{NiO}-\mathrm{CNT}\right)$, where the prefix $X$ and $Y$ represent the number of $\mathrm{NiO}$ and $\mathrm{SnO}_{2}$ ALD cycles, respectively. Generally, any of the $\left.{ }_{n} \mathrm{SMOX}\right) \mathrm{SnO}_{2}$ and ( ${ }_{p} \mathrm{SMOX}$ ) NiO are represented as SMOX or ${ }_{n, p} \mathrm{SMOX}$, where the discussion meant to be same for both types of metal oxides; in the other case, a prefix $p$ or $n$ is added as subscript to specify the $n$-type SMOX $\left(\mathrm{SnO}_{2}\right)$ or $p$-type SMOX (NiO), respectively. Scheme 1 and Table $\mathbf{S 1}$ represents the synthesis route of different core-shell heterostructures (CSHS) and the corresponding estimated thicknesses of the shell-layers, respectively.

\section{S1.3. Characterizations}

A spectroscopic ellipsometer from Sentech (SENpro) was used for estimating the $\mathrm{NiO}$ and $\mathrm{SnO}_{2}$ film thicknesses on the silicon-wafers. Powder X-ray diffraction (pXRD) patterns were obtained on a STOE STADI MP diffractometer equipped with a Dectris Mythen $1 \mathrm{~K}$ linear silicon strip detector and $\mathrm{Ge}(111)$ double-crystal monochromator with Mo K $\alpha_{1}$ radiation $(\lambda=0.7093 \AA)$ source at $40 \mathrm{kV}(U)$ and $40 \mathrm{~mA}(I)$ in transmission configuration. High-angle annular dark-field scanning transmission electron microscopy (HAADF-STEM), High-resolution transmission electron microscopy (HRTEM) and selected area electron diffraction (SAED) were performed using a FEI Talos F200S scanning/transmission electron microscope (S/TEM) operated at $200 \mathrm{kV}$. Energy dispersive X-ray (EDX) spectra and elemental mappings were recorded using the build in SuperX EDS detector. The analysis of the TEM data was performed using Velox ${ }^{\mathrm{TM}}$ software. X-ray photoelectron spectroscopy (XPS) measurements were performed using an EA 125 hemispherical analyser (Omicron) in an ultrahigh vacuum (UHV) setup (base pressure $2.10^{-10} \mathrm{mbar}$ ) and the $\mathrm{Mg} \mathrm{K} \alpha$ radiation produced from a dual anode X-ray source (DAR 400). $\mathrm{Ar}^{+}$sputtering and ultraviolet photoelectron spectroscopy (UPS) measurements were performed in another UHV setup (base pressure $1.10^{-10}$ mbar in the analysis chamber and $1.10^{-9}$ mbar in the preparation chamber) using a Phoibos 100 and a monochromatized HIS 13 helium lamp.

\section{S1.4. Device Fabrication and Sensing Measurements}

Transducer devices were consist of an alumina substrate containing interdigited platinum electrodes on top (area, ca. $6 \times 3 \mathrm{~mm}^{2}$ ) and a Pt heater printed on back-side of the substrate. A film of watery dispersed samples (any of the ${ }_{X} \mathrm{NiO}-\mathrm{CNT},{ }_{Y} \mathrm{SnO}_{2}-\mathrm{CNT},{ }_{X} \mathrm{NiO}-{ }_{Y} \mathrm{SnO}_{2}-\mathrm{CNT}$ and ${ }_{Y} \mathrm{SnO}_{2-}{ }_{-} \mathrm{NiO}-\mathrm{CNT}$ ) slurry was applied onto the platinum interdigited area of the device. After that, sensors were dried and introduced in a stainless steel chamber for the gas-sensing measurements in controlled environments. Gases supplied from certified bottles were diluted in air at required concentrations using the mass flow controllers (MFC). The dc-resistance measurements were carried out under a dry air total stream of $100 \mathrm{sccm}$ at temperature ranges $50-200^{\circ} \mathrm{C}$. A multimeter data acquisition unit (Agilent 34970A) was 
used, while a dual channel power supplier instrument Agilent E3632A was employed to bias the built in heater of the sensor to perform measurements at super-ambient temperature. The sensor response is defined as response $(\mathrm{R})=\mathrm{R}_{\mathrm{g}} / \mathrm{R}_{\mathrm{a}}$ and $\mathrm{R}_{\mathrm{a}} / \mathrm{R}_{\mathrm{g}}$ for $p$-type and $n$-type of response, respectively. Where $\mathrm{R}_{\mathrm{g}}$ and $R_{a}$ represent the electrical resistance of the sensor in presence and absence of target analytes, respectively. The comprehensive of the sensor fabrication and gas sensing measurements can be found in our earlier reports. ${ }^{[3]}$

\section{S2. Results and Discussions}

The as-synthesized ${ }_{X} \mathrm{NiO}-\mathrm{CNT},{ }_{Y} \mathrm{SnO}_{2}-\mathrm{CNT},{ }_{X} \mathrm{NiO}-{ }_{Y} \mathrm{SnO}_{2}-\mathrm{CNT}$ and ${ }_{Y} \mathrm{SnO}_{2-}{ }_{-} \mathrm{NiO}-\mathrm{CNT}$ CSHS samples were thoroughly characterized for their structures, microstructures and morphologies, and chemical states using powder X-ray diffraction (pXRD), transmission electron microscopy (TEM) and X-ray photoelectron spectroscopy (XPS).

\section{S2.1. Powder X-ray Diffraction}

The structure and phase composition of the as-synthesized samples were analysed by powder X-ray diffraction (pXRD). Figure $\mathbf{S 1}$ shows pXRD patterns for pristine-CNTs and $\mathrm{NiO}$ and $\mathrm{SnO}_{2}$-coated CNTs samples, namely ${ }_{200} \mathrm{NiO}-\mathrm{CNT},{ }_{50} \mathrm{SnO}_{2}-\mathrm{CNT},{ }_{200} \mathrm{NiO}-{ }_{50} \mathrm{SnO}_{2}-\mathrm{CNT}$ and ${ }_{50} \mathrm{SnO}_{2}{ }_{200} \mathrm{NiO}-\mathrm{CNT}$ coreshell heterostructures (CSHS). The diffractions centred at $11.9^{\circ}(2 \theta)$ can be attributed to the (002) plane for the hexagonal graphitic carbon structure (space group: P63mc (186), ICDD: 00-073-1523) from CNTs substrate. The diffractions located at $16.9^{\circ}, 19.54^{\circ}$, and $27.8^{\circ}$ correspond to (111), (200), and (220) planes of the rock salt phase of $\mathrm{NiO}$, respectively (space group: Fm $\overline{3} \mathrm{~m}$ (225), ICDD: 00073-1523). The broad diffraction peaks show the nanocrystalline nature of the NiO deposited film. ${ }^{[4]}$ This is in-line to our already reported results for the ALD-NiO on different substrates. As expected for this very thin film of $\mathrm{NiO}$ with 200 ALD cycles (ca. 5.7-6.5 nm), the diffractions intensity is quite low. However, our earlier studies with higher ALD cycles, i.e. with further increasing the thickness of the $\mathrm{NiO}$ film, showed that these reflection related to the rock-salt $\mathrm{NiO}$ phase became more pronounced. ${ }^{[5]}$ The samples coated with $\mathrm{SnO}_{2}$ only, or $\mathrm{NiO}$ and $\mathrm{SnO}_{2}$ in any sequence (i.e., ${ }_{x} \mathrm{NiO}$ ${ }_{Y} \mathrm{SnO}_{2}-\mathrm{CNT}$ and ${ }_{Y} \mathrm{SnO}_{2-}{ }_{X} \mathrm{NiO}-\mathrm{CNT}$ ), show distinctive diffractions related to the cassiterite phase of $\mathrm{SnO}_{2}$. The diffractions peaks located at $(2 \theta) 15.56^{\circ}, 17.36^{\circ}, 17.89^{\circ}, 19.35^{\circ}, 23.38^{\circ}$ and $27.54^{\circ}$ correspond to (101), (200), (111), (210), (211) and (310) planes of the tetragonal phase of $\mathrm{SnO}_{2}$, respectively (space group: P42/mnm (136), ICDD: 00-003-0439). The diffraction at $12.26^{\circ}$ corresponds to (110) plane of $\mathrm{SnO}_{2}$ (cassiterite phase) is overlapped with the (002) diffraction from the back ground of the CNT substrate. There is no diffraction which can be seen for the any other phase confirming the purity of the cassiterite $\mathrm{SnO}_{2}$ and cubic $\mathrm{NiO}$ phases in the respective samples. 


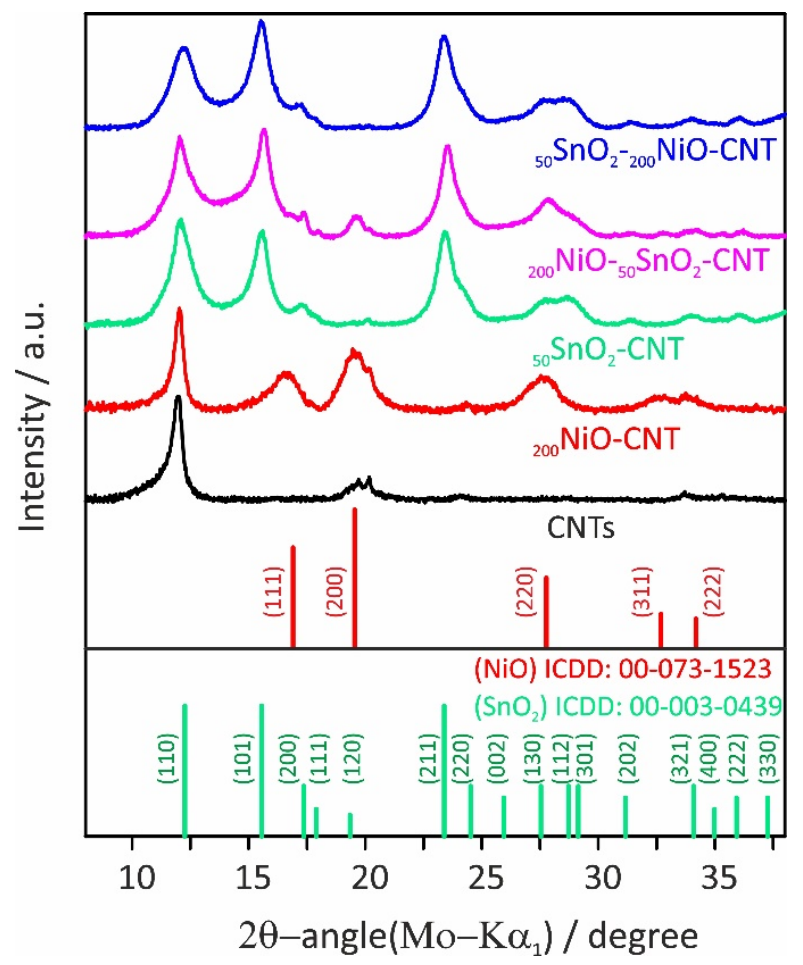

Figure S1. pXRD patterns of ${ }_{200} \mathrm{NiO}-\mathrm{CNT},{ }_{50} \mathrm{SnO}_{2}-\mathrm{CNT},{ }_{200} \mathrm{NiO}-{ }_{50} \mathrm{SnO}_{2}-\mathrm{CNT}$ and ${ }_{50} \mathrm{SnO}_{2-200} \mathrm{NiO}-\mathrm{CNT}$ CSHS samples. The pXRD pattern recorded for pristine CNTs is shown (black) as a reference of the substrate background.

\section{S2.2. Transmission Electron Microscopy}

Table S1. Detail of the ${ }_{n, p} \mathrm{SMOX}^{-C N T}$ and ${ }_{n, p} \mathrm{SMOX}_{p, n} \mathrm{SMOX} \mathrm{CNT}$ core-shell heterostructures along with the average shell thicknesses calculated from TEM micrographs and spectroscopic ellipsometry.

\begin{tabular}{|c|c|c|c|c|c|}
\hline \multirow[t]{2}{*}{$\begin{array}{l}\text { Sample } \\
\text { number }\end{array}$} & \multirow[t]{2}{*}{ Samples } & \multicolumn{2}{|c|}{$\begin{array}{l}\text { Transmission electron microscopy } \\
\text { (TEM) }\end{array}$} & \multicolumn{2}{|c|}{$\begin{array}{c}\text { Spectroscopic ellipsometry } \\
\text { (SE) }\end{array}$} \\
\hline & & $\begin{array}{l}\text { Thickness } \\
\text { NiO (nm) }\end{array}$ & $\begin{array}{c}\text { Thickness } \mathrm{SnO}_{2} \\
(\mathrm{~nm})\end{array}$ & $\begin{array}{l}\text { Thickness } \\
\text { NiO (nm) }\end{array}$ & $\begin{array}{c}\text { Thickness } \mathrm{SnO}_{2} \\
(\mathbf{n m})\end{array}$ \\
\hline I & ${ }_{20} \mathrm{SnO}_{2}-\mathrm{CNT}$ & --- & 2.9 & --- & 3.3 \\
\hline II & ${ }_{50} \mathrm{SnO}_{2}-\mathrm{CNT}$ & --- & 8.5 & --- & 9.3 \\
\hline III & ${ }_{100} \mathrm{SnO}_{2}$-CNT & --- & 17 & --- & 18.1 \\
\hline IV & ${ }_{200} \mathrm{NiO}-\mathrm{CNT}$ & 6.3 & --- & 6.7 & --- \\
\hline $\mathbf{v}$ & $\begin{array}{c}{ }_{200} \mathrm{NiO}_{-25} \mathrm{SnO}_{2-} \\
\mathrm{CNT} \\
\end{array}$ & 5.5 & 3.5 & 6.4 & 3.7 \\
\hline VI & $\begin{array}{c}{ }_{200} \mathrm{NiO}-{ }_{50} \mathrm{SnO}_{2-} \\
\mathrm{CNT} \\
\end{array}$ & 5.7 & 8.4 & 6.5 & 9.0 \\
\hline VII & $\begin{array}{l}{ }_{350} \mathrm{NiO}_{-50} \mathrm{SnO}_{2-} \\
\mathrm{CNT} \\
\end{array}$ & 9.5 & 7.7 & 9.8 & 8.8 \\
\hline VIII & $\begin{array}{l}{ }_{50} \mathrm{SnO}_{2-200} \mathrm{NiO}- \\
\mathrm{CNT}\end{array}$ & 5.9 & 7.3 & 8.5 & 8.8 \\
\hline
\end{tabular}




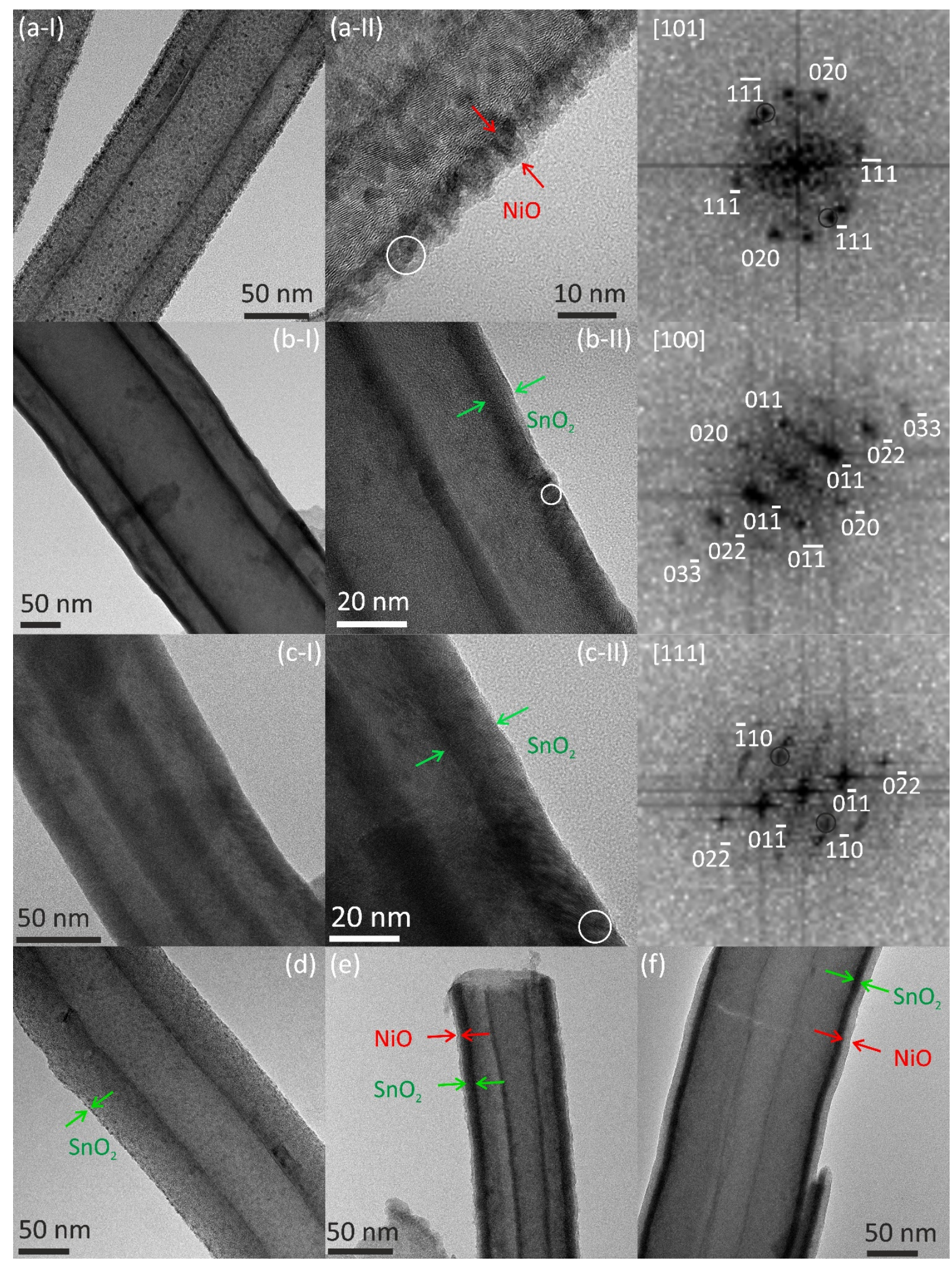

Figure S2. BF-TEM and HRTEM micrographs, and the corresponding power-spectrum for (a) ${ }_{200} \mathrm{NiO}-$ CNT, (b) ${ }_{50} \mathrm{SnO}_{2}$-CNT and (c) ${ }_{100} \mathrm{SnO}_{2}$-CNT CSHS. BF-TEM micrographs for (d) ${ }_{20} \mathrm{SnO}_{2}$-CNT, (e) ${ }_{200} \mathrm{NiO}-{ }_{50} \mathrm{SnO}_{2}-\mathrm{CNT}$ and (f) ${ }_{350} \mathrm{NiO}_{-50} \mathrm{SnO}_{2}$-CNT CSHS. $x$ and $y$ are the number of ALD cycles of the $\mathrm{NiO}$ and $\mathrm{SnO}_{2}$ process, respectively. The power spectra shown correspond to the encircled region in the same panel-row. 


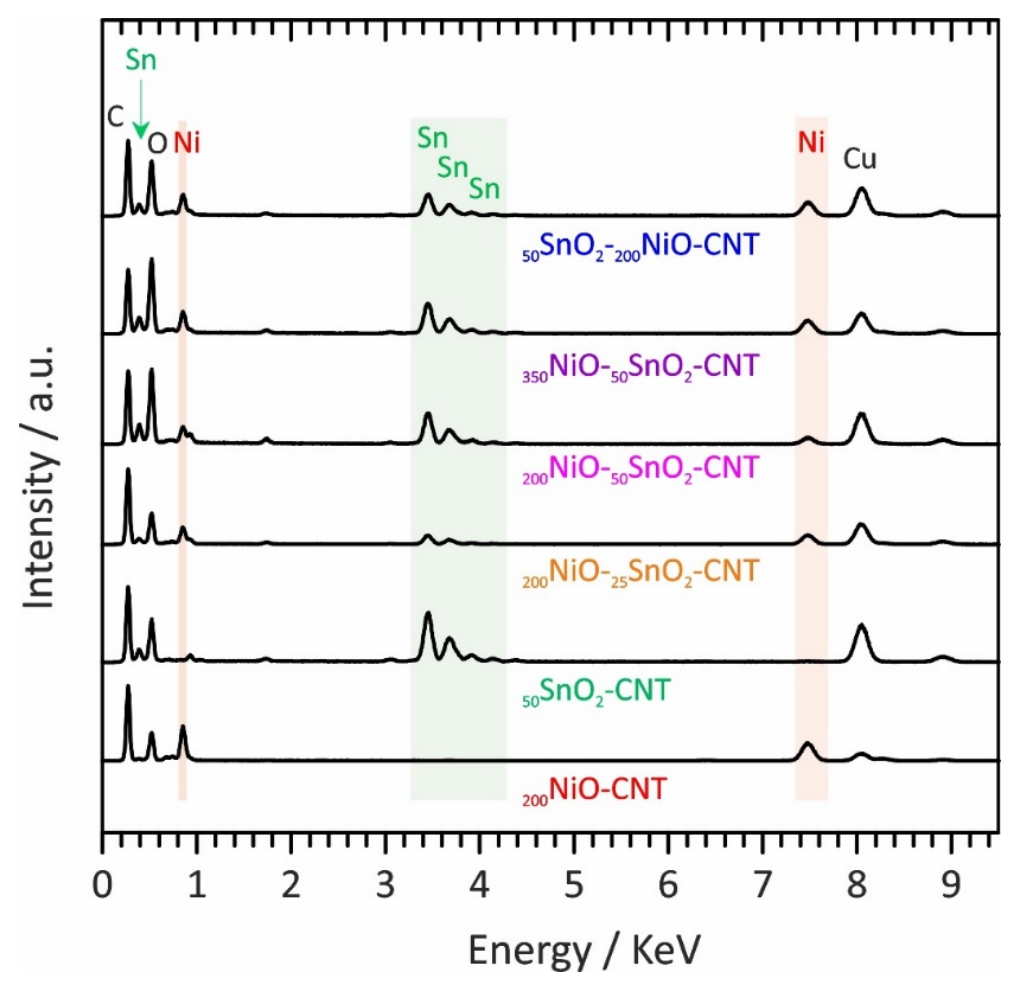

Figure S3. EDX spectra for ${ }_{200} \mathrm{NiO}-\mathrm{CNT},{ }_{50} \mathrm{SnO}_{2}-\mathrm{CNT},{ }_{200} \mathrm{NiO}_{25} \mathrm{SnO}_{2}-\mathrm{CNT},{ }_{200} \mathrm{NiO}-{ }_{50} \mathrm{SnO}_{2}-\mathrm{CNT}$, ${ }_{350} \mathrm{NiO}_{25} \mathrm{SnO}_{2}-\mathrm{CNT}$ and ${ }_{50} \mathrm{SnO}_{2-200} \mathrm{NiO}-\mathrm{CNT}$ CSHS analyzed on a copper TEM-grid.

\section{S2.3. X-ray and ultraviolet photoelectron spectroscopy}

Figure $\mathbf{S} 4$ shows the XPS survey spectra of all of the bare-CNTs, ${ }_{200} \mathrm{NiO}-\mathrm{CNT},{ }_{50} \mathrm{SnO}_{2}-\mathrm{CNT},{ }_{200} \mathrm{NiO}-$ ${ }_{50} \mathrm{SnO}_{2}-\mathrm{CNT}$ and ${ }_{50} \mathrm{SnO}_{2-200} \mathrm{NiO}-\mathrm{CNT}$ CSHS samples. All of the NiO-terminated heterostructures show $\mathrm{Ni}$-signals marked as Ni 2p and Ni LMM. Similarly, all of the $\mathrm{SnO}_{2}$-terminated heterostructures show typical Sn 4d, Sn 3d and Sn MNN signals marked accordingly (Figure S4). The intensity of the Sn signals became lower in ${ }_{200} \mathrm{NiO}_{50} \mathrm{SnO}_{2}$-CNT as compared to the ${ }_{50} \mathrm{SnO}_{2}-\mathrm{CNT}$ and ${ }_{50} \mathrm{SnO}_{2}{ }_{2}{ }_{200} \mathrm{NiO}-\mathrm{CNT}$ CSHS, confirming a comformal and homogeneous coverage of the top surface with NiO film (thickness approx. 5.8-6.3 nm, cf. HRTEM) in these heterostructures. On the other hand, NiO-related

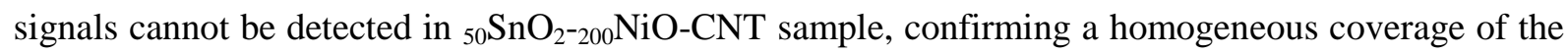
top surface with a $\mathrm{SnO}_{2}$ film (thickness approx. 8-9 nm, $c f$. HRTEM). 


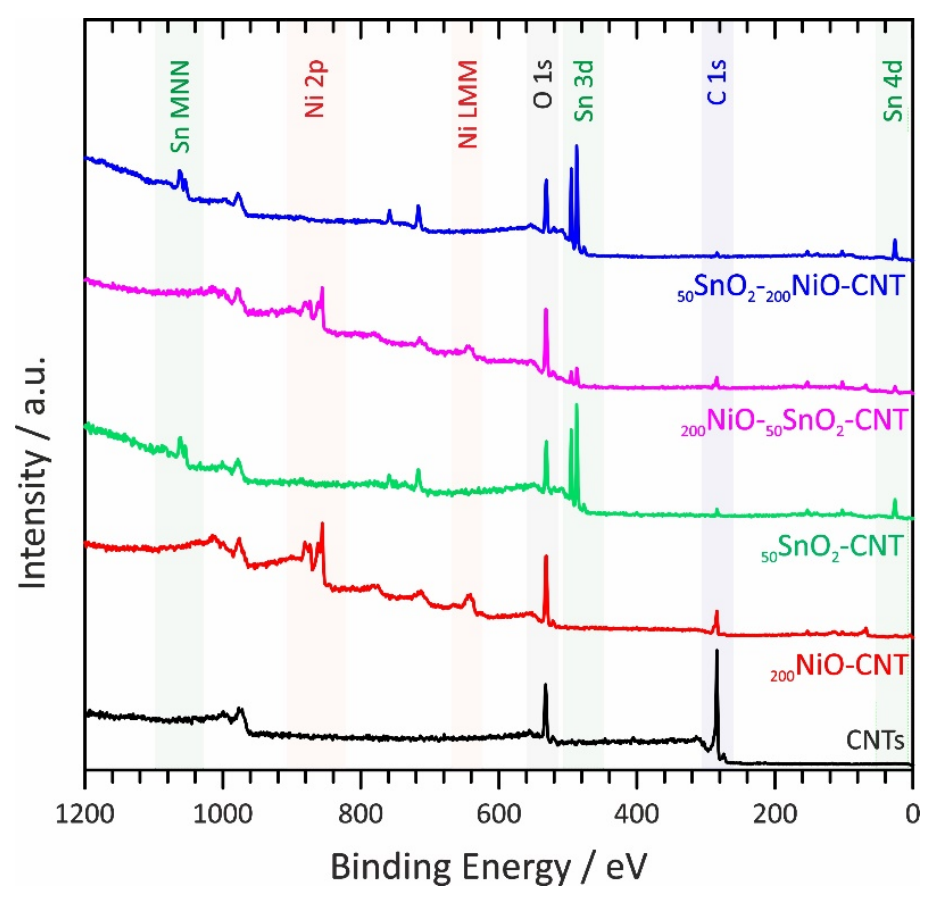

Figure S4. XPS survey spectra of bare-CNTs, ${ }_{200} \mathrm{NiO}-\mathrm{CNT},{ }_{50} \mathrm{SnO}_{2}-\mathrm{CNT},{ }_{200} \mathrm{NiO}-{ }_{50} \mathrm{SnO}_{2}-\mathrm{CNT}$ and ${ }_{50} \mathrm{SnO}_{2-200} \mathrm{NiO}-\mathrm{CNT}$ CSHS.

The chemical states of the $\mathrm{SnO}_{2}$ and $\mathrm{NiO}$ films deposited onto the CNTs were analysed by looking at X-ray-induced core level and Auger electrons spectroscopy, Figure S5-8. Figure S5a shows the Sn $3 \mathrm{~d}_{5 / 2}$ X-ray photoelectron spectrum of $\mathrm{SnO}_{2}$-coated CNTs $\left({ }_{50} \mathrm{SnO}_{2}\right.$-CNT). The $\mathrm{Sn} 3 \mathrm{~d}_{5 / 2}$ peak maximum is found at $486.95 \mathrm{eV}$ binding energy (BE). However, it is notoriously difficult to rely only on the Sn 3d core levels BE to derive the oxidation state of Sn. ${ }^{[6]}$ Therefore, we additionally examined the corresponding X-ray induced Sn MNN Auger spectra with the $\mathrm{M}_{5} \mathrm{~N}_{45} \mathrm{~N}_{45}$ peak is located at $431.9 \mathrm{eV}$ Kinetic energy (KE), Figure S5b. A close inspection of the Sn MNN spectrum reveals strong similarity to that of $\mathrm{SnO}_{2}$ in terms of line-shape and energy position, and substantial differences as compared to those of SnO. ${ }^{[6, c]}$ Therefore, we infer that the ALD growth results in the formation of $\mathrm{SnO}_{2}$, which is further substantiated below by looking at the Auger parameter and the related Wagner plot (Figure S8b).

Figure S5c,d shows the X-ray induced Ni 2p core level and Ni LMM Auger spectra of NiO-coated CNTs $\left({ }_{200} \mathrm{NiO}-\mathrm{CNT}\right)$. For the $\mathrm{Ni} 2 \mathrm{p}_{3 / 2}$, the broad feature centred at $861.2 \mathrm{eV}$ is mainly due to the complex multiplet splitting and to the number of possible final states due to the strong overlap of the $\mathrm{Ni}$ and O orbitals. ${ }^{[7]}$ Most relevant is the peak at $856.5 \mathrm{eV} \mathrm{BE}$, which is due to the formation of hydroxide-terminated $\mathrm{NiO}, \mathrm{Ni}(\mathrm{OH})_{2}$, in the surface region. ${ }^{[1 \mathrm{~b}, 3,8]}$ We also remark that no characteristic peak of $\mathrm{NiO}$, usually found around $854( \pm 0.5) \mathrm{eV} \mathrm{BE}$, can be observed. This suggests that hydroxylation of the surface occurs rapidly, at least within the time frame of sample transfer from the ALD chamber to the photoemission setup. ${ }^{[1 b, 8 b]}$

To confirm the formation of $\mathrm{NiO}$ in the bulk, we additionally proceeded with mild Ar-ion sputtering $\left(500 \mathrm{eV} ; \Delta \mathrm{t}=60 \mathrm{~s}\right.$; sample current $\mathrm{I}_{\mathrm{s}}=1 \mu \mathrm{A}$ ) of the sample. Importantly, the results of the sputtered sample, which are shown in Figure S6, reveal the emergence of a low energy component at $853.5 \mathrm{eV}$ $\mathrm{BE}$ in the $\mathrm{Ni} 2 \mathrm{p}_{3 / 2}$ spectrum (Figure S6a), which can readily be attributed to the presence NiO. ${ }^{[3,5,8]}$ Further confirmation of the surface and bulk nickel oxide compounds (as already confirmed also by XRD, SAED, $c f$. Figure 1 and S1,2) is provided by looking at the Auger LMM spectra displayed in Figure S6b, which shows an energy shift of $1.3 \mathrm{eV}$ of the $\mathrm{L}_{3} \mathrm{M}_{45} \mathrm{M}_{45}$ peak to higher $\mathrm{KE}$ after 
sputtering, in very good agreement with existing reports of the Auger spectra of $\mathrm{Ni}(\mathrm{OH})_{2}$ and $\mathrm{NiO}$ (Figure S8a). ${ }^{[8]}$
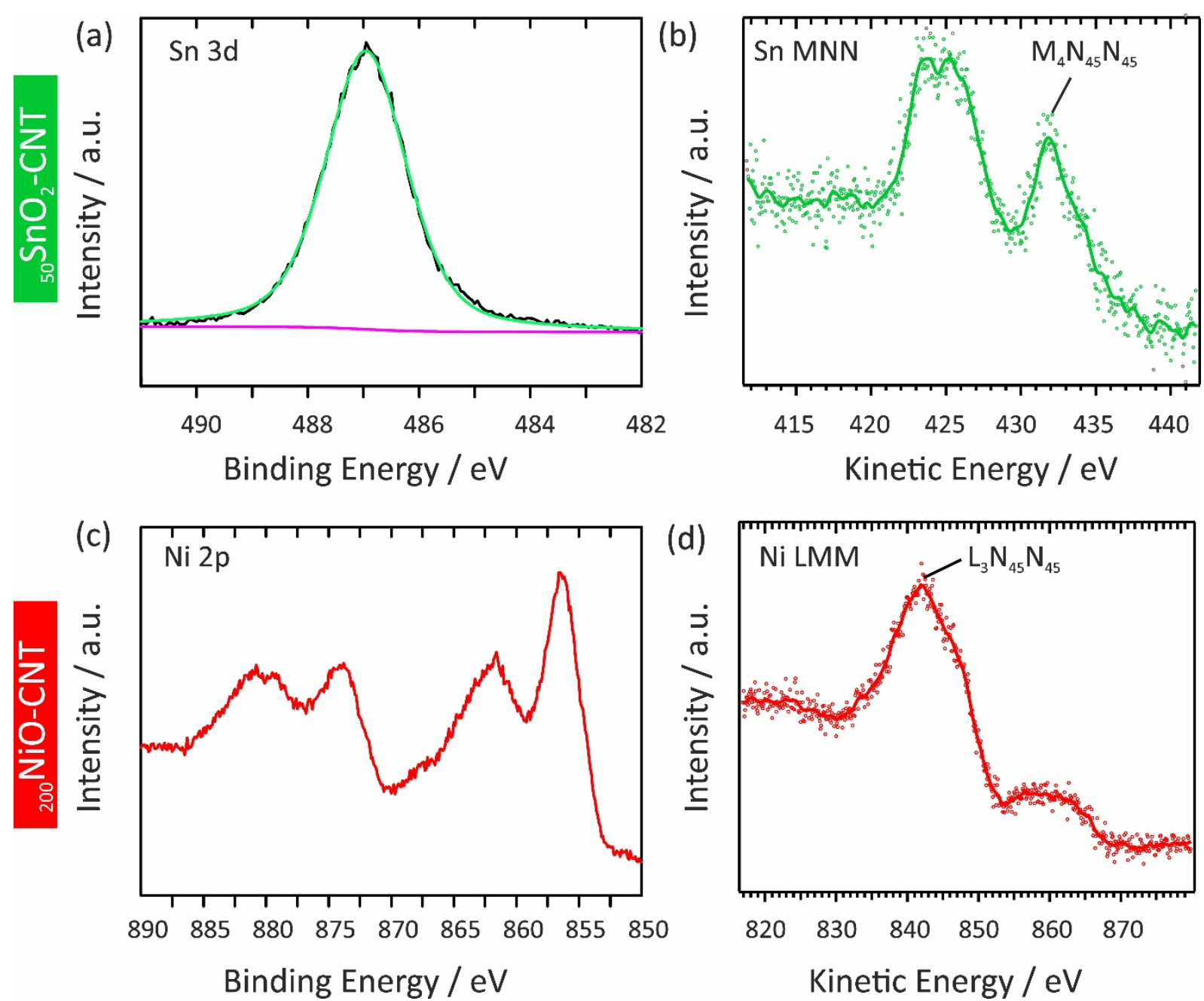

Figure S5. (a) Sn 3d photoelectron spectrum and (b) Sn MNN Auger spectrum of $\mathrm{SnO}_{2}$-coated CNTs ( ${ }_{50} \mathrm{SnO}_{2}$-CNT CSHS). (c) Ni 2p2/3 photoelectron spectrum and (d) Ni LMM Auger spectrum of NiOcoated CNTs ( ${ }_{200} \mathrm{NiO}-\mathrm{CNT}$ CSHS).
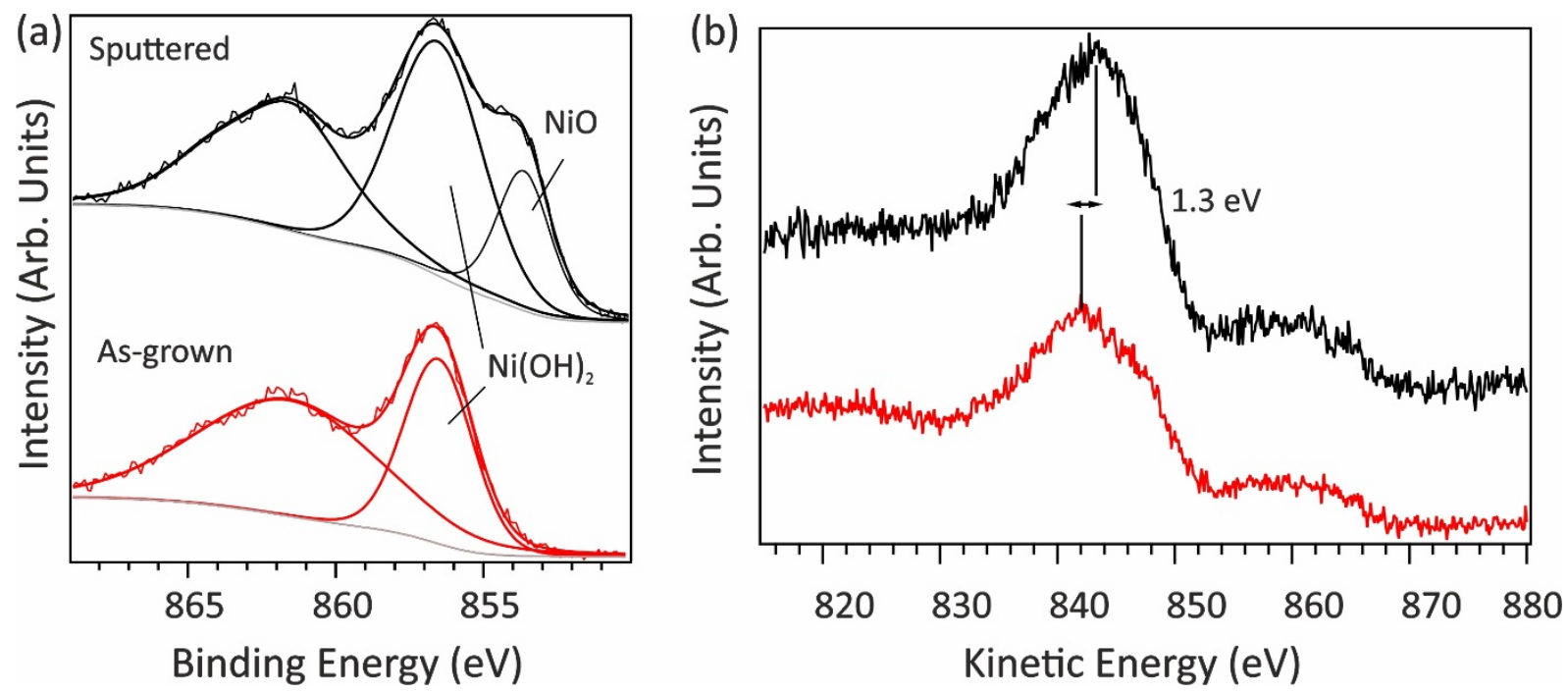
Figure S6. (a) Ni 2p3/2 and (b) Ni LMM spectra of as-grown (red) and mildly Ar-ion sputtered (black) ${ }_{200} \mathrm{NiO}-\mathrm{CNT} \mathrm{CSHS}$ revealing the presence of $\mathrm{NiO}$ after sputtering.

Figure S7 shows the $\mathrm{Sn} 3 \mathrm{~d}_{5 / 2}$, $\mathrm{Ni} 2 \mathrm{p}$, Sn MNN spectra of the ${ }_{200} \mathrm{NiO}-{ }_{50} \mathrm{SnO}_{2}-\mathrm{CNT}$ (a, b, c) heterostructure and the $\mathrm{Sn} 3 \mathrm{~d}_{5 / 2}$, Ni 2p, Ni LMM spectra of the ${ }_{50} \mathrm{SnO}_{2}{ }^{-200} \mathrm{NiO}-\mathrm{CNT}$ (d, e, f) heterostructure. In the case of ${ }_{200} \mathrm{NiO}_{-50} \mathrm{SnO}_{2}-\mathrm{CNT}$, the $\mathrm{Sn} 3 \mathrm{~d}$ intensity is strongly reduced as compared to that of $\mathrm{SnO}_{2}$-terminated heterostructures (see survey XPS in Figure S4) but the peak shape and energy remains virtually identical to those of uncovered $\mathrm{SnO}_{2}$, which demonstrates that $\mathrm{NiO}$ effectively covers the $\mathrm{SnO}_{2}$ film. In addition, the Ni 2p and LMM spectra are also virtually identical to those measured when $\mathrm{NiO}$ is grown directly on CNTs, which suggests that the substrate does not strongly influence the formation of the $\mathrm{NiO}$ film away from the interface. For ${ }_{50} \mathrm{SnO}_{2}{ }^{-}{ }_{200} \mathrm{NiO}-\mathrm{CNT}$, we observe no more XPS signal from $\mathrm{NiO}$, unambiguously demonstrating the homogenous coverage of the NiO film below $\mathrm{SnO}_{2}$. There as well, the $\mathrm{Sn} 3 \mathrm{~d}$ and MNN spectra are virtually identical both in terms of lineshape and peak position to those of $\mathrm{SnO}_{2}$ grown directly onto the CNTs.
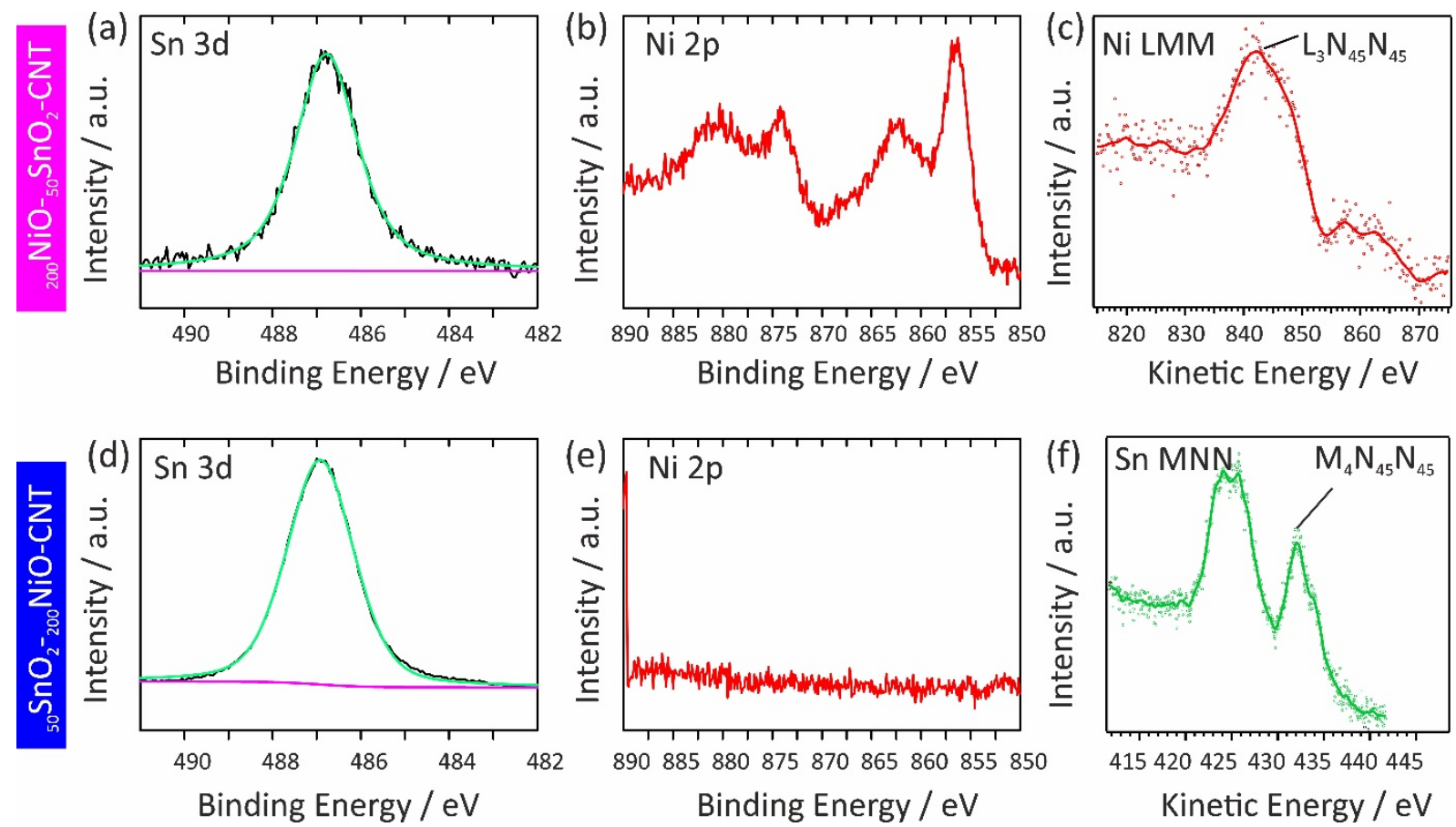

Figure S7. (a) Sn 3d, (b) Ni 2p and (c) Ni LMM spectra of ${ }_{200} \mathrm{NiO}_{-50} \mathrm{SnO}_{2}-\mathrm{CNT}$ heterostructures. (d) $\mathrm{Sn} 3 \mathrm{~d}(\mathrm{e}) \mathrm{Ni} 2 \mathrm{p}$ and (f) $\mathrm{Sn} \mathrm{MNN}$ spectra of ${ }_{50} \mathrm{SnO}_{2-200} \mathrm{NiO}-\mathrm{CNT}$ heterostructures.

In order to ascertain the oxidation state of the metal in the as-grown metal oxides, we determined the modified Auger parameter $\alpha^{\prime}$, with $\alpha^{\prime}=\mathrm{E}_{\mathrm{b}}\left(2 \mathrm{p}_{3 / 2}\right)+\mathrm{E}_{\mathrm{k}}\left(\mathrm{L}_{3} \mathrm{M}_{45} \mathrm{M}_{45}\right)$ for $\mathrm{Ni}$ and $\alpha^{\prime}=\mathrm{E}_{\mathrm{b}}\left(3 \mathrm{~d}_{5 / 2}\right)+$ $E_{k}\left(M_{4} N_{45} N_{45}\right)$ for Sn. $E_{b}$ represents the binding energy of the photoelectrons emitted from the Ni $2 p_{3 / 2}$ or $\mathrm{Sn} 3 \mathrm{~d}_{5 / 2}$ core levels and $\mathrm{E}_{\mathrm{k}}\left(\mathrm{L}_{3} \mathrm{M}_{45} \mathrm{M}_{45}\right)$ and $\mathrm{E}_{\mathrm{k}}\left(\mathrm{L}_{4} \mathrm{M}_{45} \mathrm{M}_{45}\right)$ is the kinetic energy of the corresponding $\mathrm{Ni}$ and Sn Auger electrons, respectively. ${ }^{\left[{ }^{[9]}\right.}$ As compared to simply relying at the binding energy of a core level, the modified Auger parameter is a quantity that has the advantage of being independent of an absolute energy reference and has developed as an established method for determining the oxidation state of a given element. ${ }^{[9 b, c]}$ To do so, the Auger electron $E_{k}$ of the element under investigation is plotted against the core level $\mathrm{E}_{\mathrm{b}}$ in a so-called Wagner plot, in which $\alpha^{\prime}$ and the overall $\left(E_{B}, E_{k}\right)$ position in the Wagner plot is representative of the formed compound and the related oxidation state of the element being investigated. ${ }^{[9 a, c]}$ The obtained Wagner plots representative of the grown nickel and tin oxides in this work are plotted in Figure S8a,b together with those already published for 
other plausible Ni and Sn oxide compounds. ${ }^{[8 a, 10]}$ From this, it appears clearly that the surface of the as-grown and sputtered nickel oxide compounds consists of hydroxylated-NiO, $\mathrm{Ni}(\mathrm{OH})_{2}$, and $\mathrm{NiO}$, respectively, while the ALD of tin oxide results in the formation of $\mathrm{SnO}_{2}$.
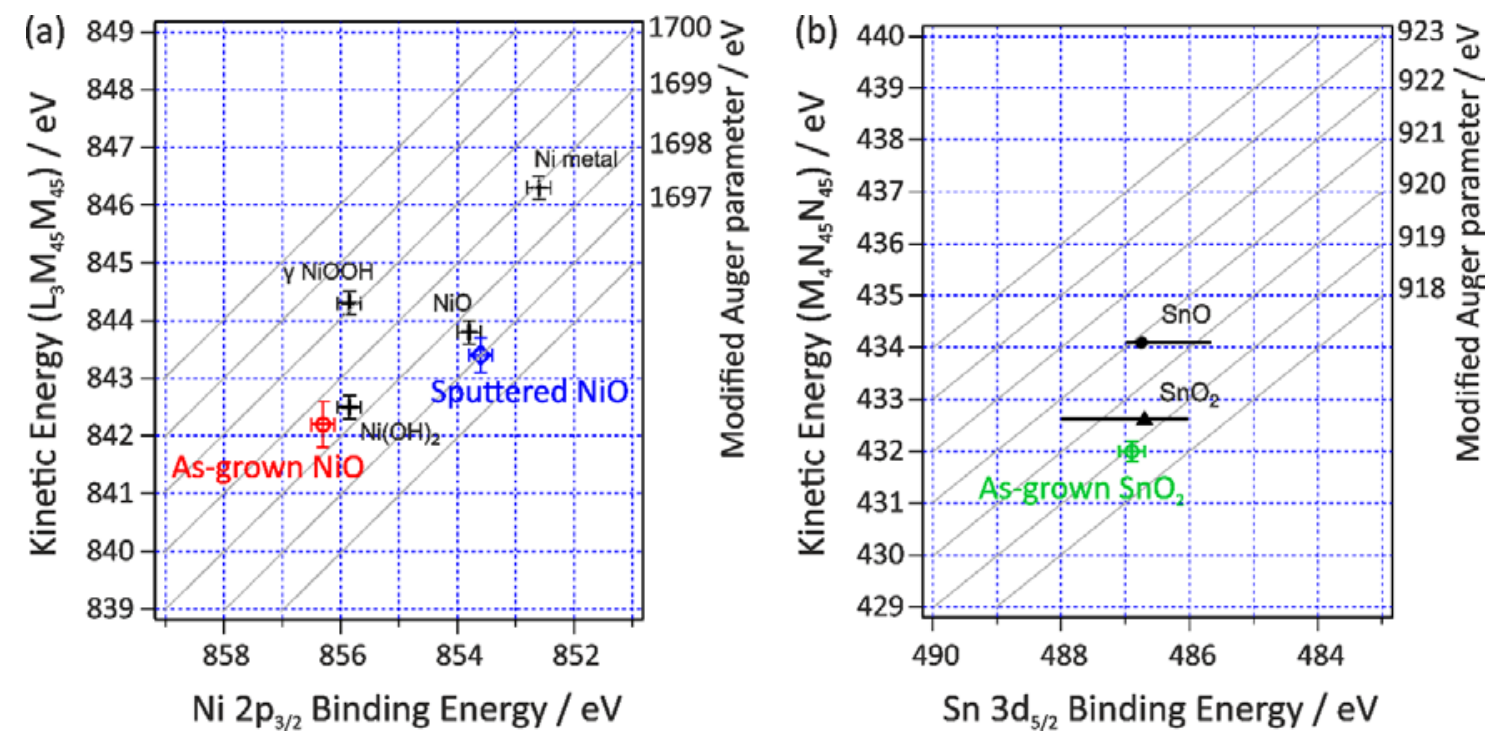

Figure S8. (a) $\mathrm{Ni} 2 \mathrm{p}_{3 / 2}-\mathrm{Ni} \mathrm{L} \mathrm{L}_{3} \mathrm{M}_{45} \mathrm{M}_{45}$, and (b) Sn $3 \mathrm{~d}_{5 / 2}-\mathrm{Sn} \mathrm{M}_{4} \mathrm{~N}_{45} \mathrm{~N}_{45}$ Wagner (chemical state) plots including a comparison of the present data and literature (black symbols) adapted from the cited references. ${ }^{[8 \mathrm{a}, 10]}$ Constant Auger parameter lines are also plotted together with their corresponding $\alpha^{\prime}$ values on the right side of the graph (grey-lines).

Having assessed that the formation of $\mathrm{SnO}_{2}$ and hydroxide-terminated $\mathrm{NiO}$ films as a result of the ALD process, we now look at the XPS valence band features in. For $\mathrm{SnO}_{2}$ grown on CNTs and NiO, we find that the valence band spectra present similar line-shape with the valence band onset at $2.45 \mathrm{eV}$ $\pm 0.15 \mathrm{eV}$ BE in good agreement with earlier studies. ${ }^{[6 \mathrm{~b}, 11]}$ In addition, we may observe an additional density of states peaking at ca. $2.15 \mathrm{eV} \mathrm{BE}$ and extending up to $1.55 \mathrm{eV} \mathrm{BE}$, which could be attributed to surface states due to missing $\mathrm{O}$ atoms, Figure S9a. For hydroxylated $\mathrm{NiO}$ film grown on ${ }_{50} \mathrm{SnO}_{2} / \mathrm{CNTs}$ and CNTs, we again find very comparable spectra, also in good agreement with $\mathrm{Ni}(\mathrm{OH})_{2} / \mathrm{NiO}$ spectra in the literature. ${ }^{[12]}$ The valence band onsets of $\mathrm{NiO}$ are determined at $1.2 \mathrm{eV} \mathrm{BE}$ and $1.0 \mathrm{eV} \mathrm{BE}$ on ${ }_{50} \mathrm{SnO}_{2} / \mathrm{CNTs}$ and on CNTs, respectively, which is in the expected energy range for $\mathrm{NiO}$, Figure S9a. ${ }^{[8,, 12]}$ In addition, one notices a tail of states extended almost up to close the Fermi level $\left(E_{F}\right)$, which might be due to the presence of $\mathrm{NiO}$ underneath the hydroxylated layer. ${ }^{[12]}$ More surface sensitive ultraviolet photoelectron spectroscopy (UPS) measurements were then performed on as-grown and mildly sputtered ${ }_{200} \mathrm{NiO}-\mathrm{CNTs}$. The results presented in Figure S9b on semi-log scale confirm that the valence band onsets are located at ca $1.1 \mathrm{eV} \mathrm{BE}$ and ca $0.2 \mathrm{eV} \mathrm{BE}$ for the as-grown and mildly sputtered ${ }_{200} \mathrm{NiO} / \mathrm{CNTs}$, respectively. 
(a)

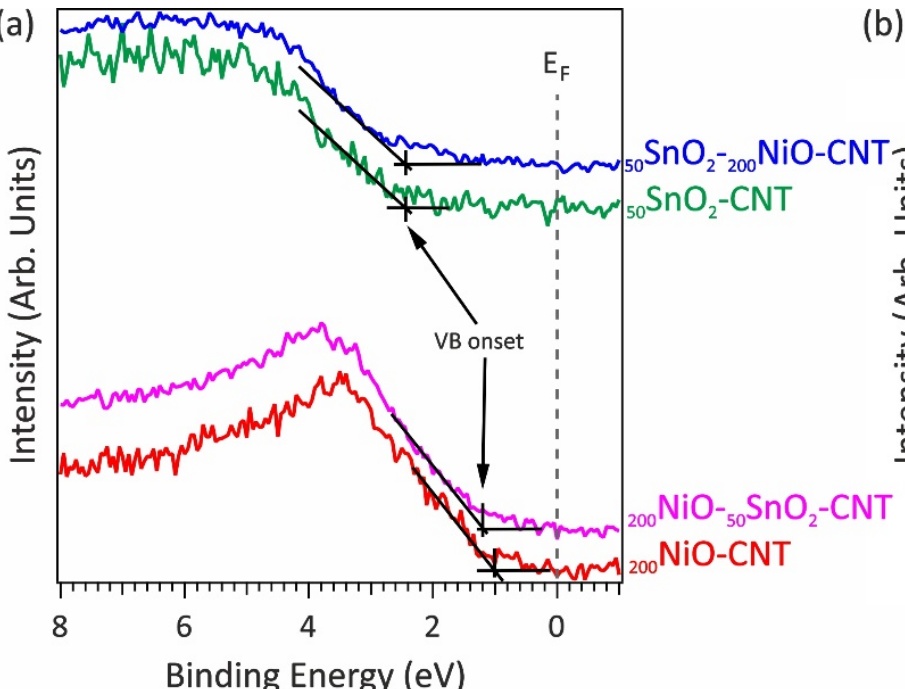

(b)

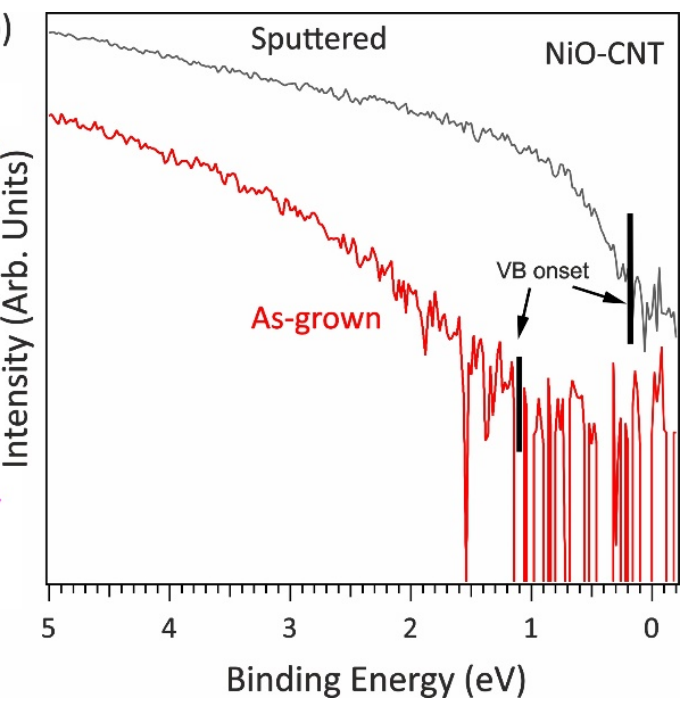

Figure S9. (a) XPS valence band spectra of ${ }_{200} \mathrm{NiO}-\mathrm{CNT},{ }_{200} \mathrm{NiO}-{ }_{50} \mathrm{SnO}_{2}-\mathrm{CNT},{ }_{50} \mathrm{SnO}_{2}-\mathrm{CNT}$, and ${ }_{50} \mathrm{SnO}_{2-200} \mathrm{NiO}$-CNT. (b) UPS valence band spectra of ${ }_{200} \mathrm{NiO}-\mathrm{CNT}$ before and after mild sputtering.

From these results, we found that the ALD growth sequence did not markedly impact the energy levels of the materials 'surface so that both sequence of deposition can be summarized in one diagram. Assuming bandgaps of $3.6 \mathrm{eV}$ for $\mathrm{SnO}_{2}{ }^{[13]}$ and 3.6-4.2 eV for NiO,${ }^{[14]}$ we can draw in Figure S10 the energy level diagram of the $\mathrm{SnO}_{2} / \mathrm{NiO}$ and $\mathrm{NiO} / \mathrm{SnO}_{2}$ heterojunctions, which corresponds to that of a $p-n$ junction in which $\mathrm{SnO}_{2}$ and $\mathrm{NiO}$ are the $n$ - and $p$-type semiconductors, respectively.

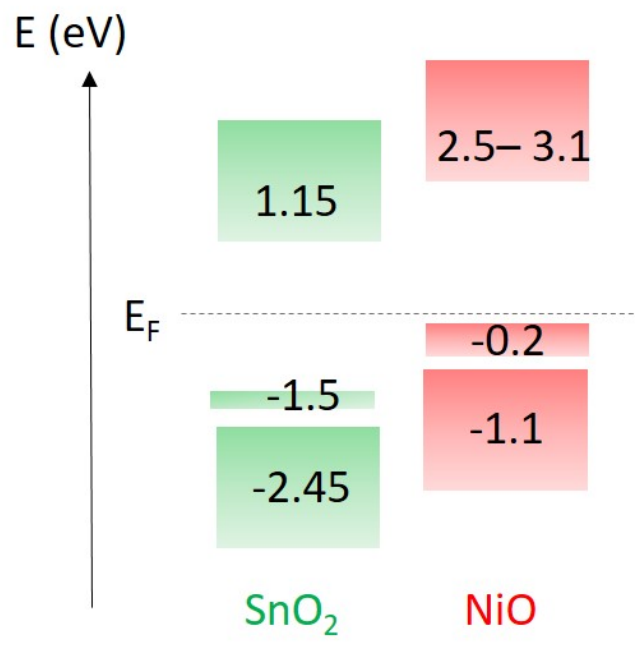

Fig. S10. Energy level diagram of the $\mathrm{SnO}_{2} / \mathrm{NiO}\left(\right.$ or $\mathrm{NiO} / \mathrm{SnO}_{2}$ ) core-shell heterostructures including the experimentally determined valence energy levels of $\mathrm{NiO}(-0.2 \mathrm{eV})$, hydroxylated-NiO $(-1.1 \mathrm{eV})$, $\mathrm{SnO}_{2}(-2.45 \mathrm{eV})$ and $\mathrm{SnOx}$-related surface states $(-1.5 \mathrm{eV})$ and conduction energy level from literature. ${ }^{[13-14]}$

\section{S2.4. Gas Sensing Mechanism}

The isothermal dynamic responses of all of the sensors fabricated with ${ }_{200} \mathrm{NiO}-\mathrm{CNT},{ }_{50} \mathrm{SnO}_{2}-\mathrm{CNT}$, ${ }_{200} \mathrm{NiO}-{ }_{50} \mathrm{SnO}_{2}-\mathrm{CNT},{ }_{50} \mathrm{SnO}_{2}{ }_{200} \mathrm{NiO}-\mathrm{CNT},{ }_{350} \mathrm{NiO}-{ }_{50} \mathrm{SnO}_{2}-\mathrm{CNT}$ and ${ }_{200} \mathrm{NiO}_{25} \mathrm{SnO}_{2}-\mathrm{CNT}$ CSHS were measured toward hydrogen (prototype of reducing gas) at a temperature range $50-200{ }^{\circ} \mathrm{C}$ (Figure S11,12). The ${ }_{200} \mathrm{NiO}-\mathrm{CNT}$ and ${ }_{50} \mathrm{SnO}_{2}$-CNT sensors showed a typical $p$ - (an increased in resistance induced by a reducing gas) and $n$-type (a decrease in resistance induced by a reducing gas) sensing response, respectively. ${ }^{[3,15]}$ 
The generally accepted gas sensing mechanism for SMOX-based gas sensors is correlated with a change of electrical resistance/conductance of the system as a result of oxygen-mediated (chemisorbed oxygen species: $\mathrm{O}^{2-}, \mathrm{O}_{2}^{-}$and $\mathrm{O}^{-}$) interaction of gaseous analytes to the surface of the sensing films. ${ }^{[15 b, 16]}$ In the case of $n$-type SMOX, the oxygen species absorbed onto the surface (by capturing electrons from the conduction band of $n$-type SMOX) lead to the formation of an electron-depletionlayer (EDL) which induces an upward band bending and an increase in the electrical resistance of the system. ${ }^{[15 c, 16 b, 17]}$ In the presence of a reducing gas such as hydrogen, the chemisorbed oxygen ions react with hydrogen species donating electrons back to the conduction band of $n$-type SMOX $\left(\mathrm{SnO}_{2}\right){ }^{[14 \mathrm{c}]}$ This decreases the width of EDL and accordingly decreases the resistance of the system. ${ }^{[15 c, 16 b, 18]}$

In the case of a p-type SMOX such as NiO, oxygen species withdraw electrons from the valence band of NiO, creating a hole-accumulation-layer (HAL), leading to a decrease of the resistance of the system. ${ }^{[3,16 b]}$ In the presence of a reducing gas, such as hydrogen, reacts with chemisorbed oxygen ions, donating electrons back to the p-type SMOX narrowing the HAL and thus increases the resistance of the system. ${ }^{[3,14 c, 15 d, 19]}$

In both of the NiO-CNT and $\mathrm{SnO}_{2}$-CNT CSHS in the current study, there is no direct contact between the CNTs-cores. i.e. CNT-CNT homojunction do not exist due to the confomal coatings achieved by ALD. Each SMOX-CNT element is connected with another SMOX-CNT element ( $c f$. gas-sensing device fabrication and measurements section, above) by SMOX shell-shell homojunctions (Figure 3). ${ }^{[3,17 b]}$

It is well known that composite materials, consisting of different metal oxides show different electrical properties and sensing behavior from their any of the single components. In the case of $\mathrm{NiO}-\mathrm{SnO}_{2}$ $\mathrm{CNT}$ or $\mathrm{SnO}_{2}$-NiO-CNT heterostructures, the interaction with the analytes occurs at the surface (whether NiO-terminated or $\mathrm{SnO}_{2}$-terminated), i.e. the receptor function. On the other hand, the charge transport is affected (i.e. the transduction mechanism) due to the change of the contacts and accordingly the serial resistances. As a result, the deposition of $\mathrm{NiO}$ onto $\mathrm{SnO}_{2}$ or vice versa, leads to the recombination of opposite charges at the $p$ - $n$ interface and thus an additional charge transport barriers is created, i.e. a Schottky barrier across the $n$ (core) $-p$ (shell) or $p$ (shell) $-n$ (core) interface. The formation of a $p-n$ heterojunction is traduced by the addition of a resistance element to the system, thus, it is expected that the resistance of the whole system increases. ${ }^{[3,14 c, 19]}$ Even though, in all SMOX-CNT or SMOX-SMOX-CNT systems, the electrons flow through the CNT conductive core, the sensing-response is governed by the modulation of resistances of both SMOX and of the one at the SMOX-SMOX interface ( $c$. Figure 3) ${ }^{[19-20]}$ Due to the low resistance of the CNTs, the modulation of their resistance if any will not be significant and therefore would not affect the sensing-response. ${ }^{[3]}$ The width of the depletion region $(L)$ can be expressed as equation (1).

$L=\lambda_{\mathrm{D}} \sqrt{\frac{2 e V_{c}}{k T}}$

where $\lambda_{\mathrm{D}}$ is the Debye length of the material, $e V_{c}$ is the surface potential, and $k T$ is the thermal energy. ${ }^{[16 b, 21]}$ It demonstrates that $L$ depends on the absorbed oxygen species and the electron density in the conduction band. Because the length of the depletion region is related directly to the $\lambda_{\mathrm{D}}$, it demonstrates that the film will be fully depleted at a thickness comparable to the $\lambda_{\mathrm{D}}$ of the material. ${ }^{[3,14 c, 19]}$ Therefore, a film with a thickness comparable to the $\lambda_{D}$ shows a pronounced modulation of the electrical conductance/resistance of the system and the surface depletion contribution becomes dominant. On the other hand, at higher shell thicknesses, the depletion of charge carriers is limited to the surface of the material and the contribution from the bulk of the material becomes important. Thus, it is well accepted that the sensing response can be optimized by optimizing 
the thickness (comparable to the Debye length of the material) of the films, where the film (shelllayer) fully participates in resistance/conductance modulation. The Debye length can be represented as equation (2). ${ }^{[22]}$

$\lambda_{\mathrm{D}}=\sqrt{\frac{k T \varepsilon}{q^{2} n_{c}}}$

Where $k$ is the Boltzmann constant, $\varepsilon$ is a dielectric constant, $T$ is the absolute temperature, $n_{c}$ is the carrier concentration and $q$ is the electric charge ${ }^{[22 a]}$. Since $\lambda_{\mathrm{D}}$ depends also on the working temperature and on the concentration of charge carriers, the reported $\lambda_{\mathrm{D}}$ values for $\mathrm{NiO}$ and $\mathrm{SnO}_{2}$ lay in a considerably large-range of $2-13^{[3,14 c, 23]}$ and $4-43 \mathrm{~nm},{ }^{[16 b, 18,22 b, 24]}$ respectively. 

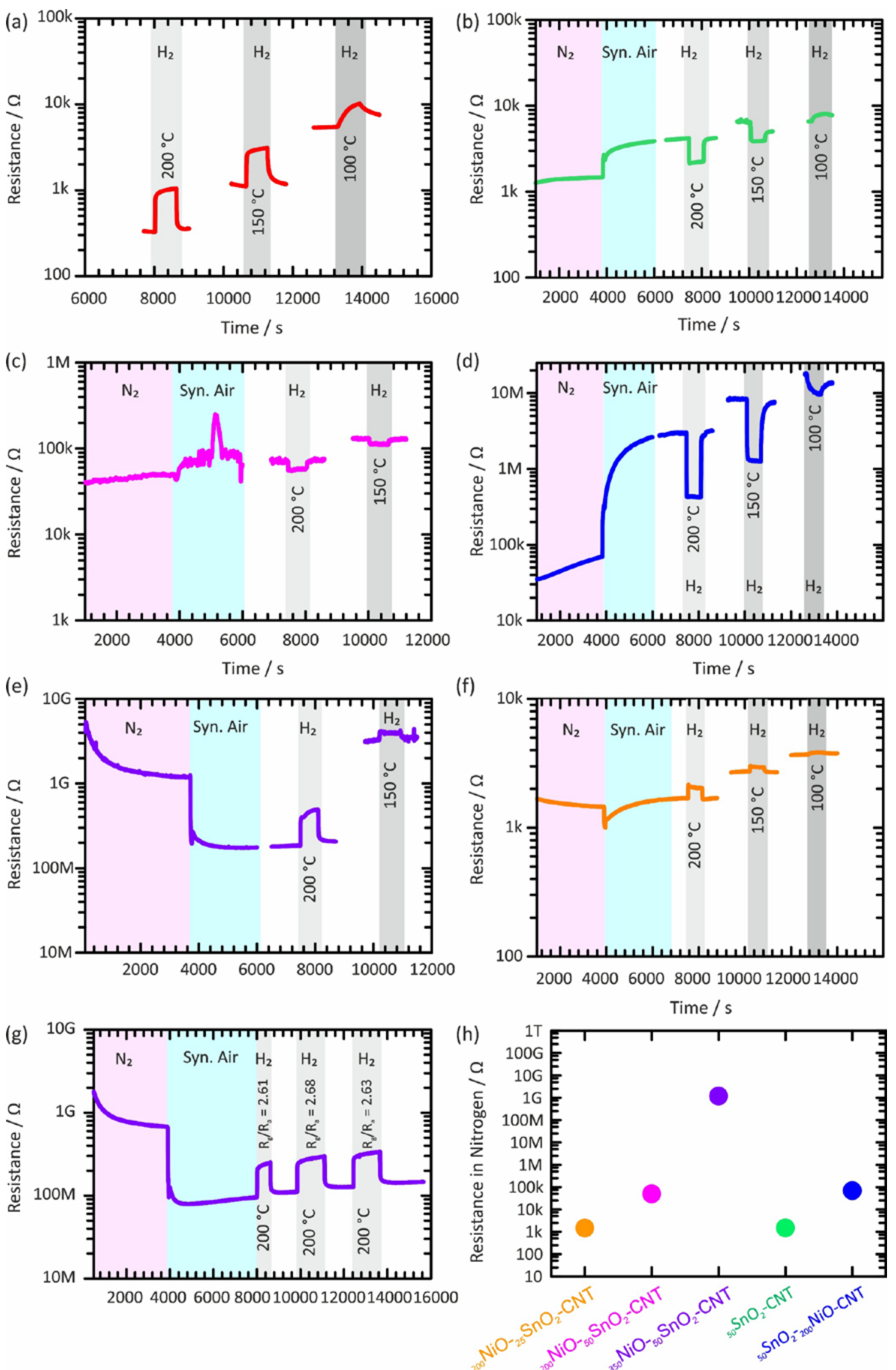

Figure S11. Transient response curves of all of the sensors fabricated at temperature ranges 100$200{ }^{\circ} \mathrm{C}$ toward $\mathrm{H}_{2}$ (5000 ppm) in dry air, (a) ${ }_{200} \mathrm{NiO}-\mathrm{CNT}$, (b) ${ }_{50} \mathrm{SnO}_{2}-\mathrm{CNT}$, (c) ${ }_{200} \mathrm{NiO}_{-50} \mathrm{SnO}_{2}-\mathrm{CNT}$, (d) ${ }_{50} \mathrm{SnO}_{2-200} \mathrm{NiO}-\mathrm{CNT}$, (e) ${ }_{350} \mathrm{NiO}_{50} \mathrm{SnO}_{2}-\mathrm{CNT}$ and (f) ${ }_{200} \mathrm{NiO}_{25} \mathrm{SnO}_{2}-\mathrm{CNT}$ core-shell 
heterostructures. (g) Transients for ${ }_{350} \mathrm{NiO}_{50} \mathrm{SnO}_{2}$-CNT sensor repeated at $200{ }^{\circ} \mathrm{C}$, showing a good repeatability of the signals. (h) The baseline resistance of the sensors in nitrogen at $200{ }^{\circ} \mathrm{C}$.
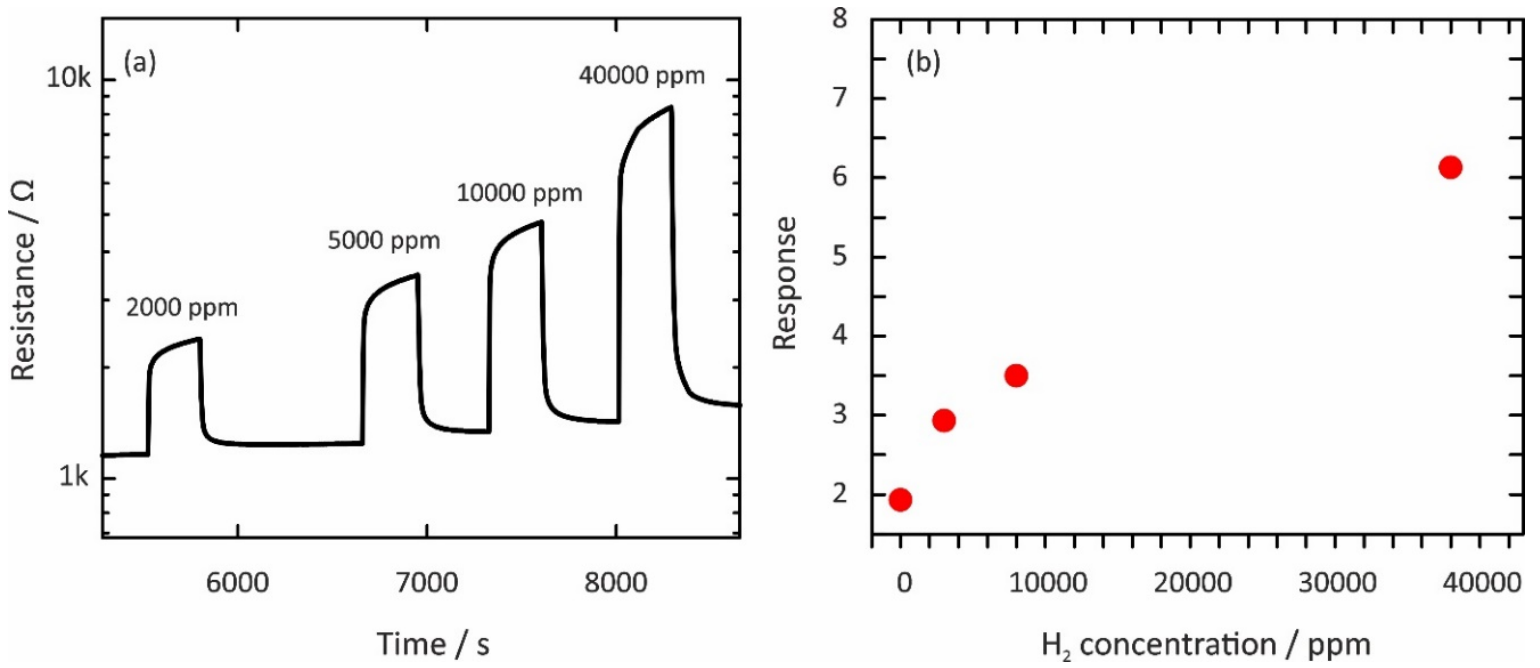

Figure S12. (a) Isothermal transient response curves for ${ }_{200} \mathrm{NiO}-\mathrm{CNT}$ CSHS sensor at $200{ }^{\circ} \mathrm{C}$ toward different concentrations of $\mathrm{H}_{2}(2000-40000 \mathrm{ppm})$ in dry air. (b) Responses as a function of hydrogen concentrations for ${ }_{200} \mathrm{NiO}-\mathrm{CNT}$ sensor at $200{ }^{\circ} \mathrm{C}$.

\section{References}

[1] a) Y. Wu, M. H. Raza, Y.-C. Chen, P. Amsalem, S. Wahl, K. Skrodczky, X. Xu, K. S. Lokare, M. Zhukush, P. Gaval, N. Koch, E. A. Quadrelli and N. Pinna, Chem. Mater. 2019, 31, 1881-1890; b) Y. Fan, Y. Wu, G. Clavel, M. H. Raza, P. Amsalem, N. Koch and N. Pinna, ACS Appl. Energy Mater. 2018, 1, 4554-4563.

[2] a) C. Marichy, J.-P. Tessonnier, M. C. Ferro, K.-H. Lee, R. Schlögl, N. Pinna and M.-G. Willinger, J. Mater. Chem. 2012, 22, 7323-7330; b) C. Marichy, A. Pucci, M.-G. Willinger and N. Pinna, Coating of Carbon Nanotubes. In Atomic Layer Deposition of Nanostructured Materials, Wiley-VCH, 2012, p; c) C. Marichy and N. Pinna, Coord. Chem. Rev. 2013, 257, 3232-3253.

[3] M. H. Raza, K. Movlaee, S. G. Leonardi, N. Barsan, G. Neri and N. Pinna, Adv. Funct. Mater. 2020, 30, 1906874.

[4] N. Pinna in X-Ray Diffraction from Nanocrystals, Eds.: N. Stribeck and B. Smarsly), Springer Berlin Heidelberg, Berlin, Heidelberg, 2005, pp. 29-32.

[5] M. H. Raza, K. Movlaee, Y. Wu, S. M. El-Refaei, M. Karg, S. G. Leonardi, G. Neri and N. Pinna, ChemElectroChem 2019, 6, 383-392.

[6] a) L. Kövér, Z. Kovács, R. Sanjinés, G. Moretti, I. Cserny, G. Margaritondo, J. Pálinkás and H. Adachi, Surf. Interface Anal. 1995, 23, 461-466; b) J.-M. Themlin, M. Chtaïb, L. Henrard, P. Lambin, J. Darville and J.-M. Gilles, Phys. Rev. B 1992, 46, 2460-2466; c) M. A. Stranick and A. Moskwa, Surf. Sci. Spectra 1993, 2, 50-54.

[7] D. Alders, F. C. Voogt, T. Hibma and G. A. Sawatzky, Phys. Rev. B 1996, 54, 7716-7719.

[8] a) M. C. Biesinger, L. W. M. Lau, A. R. Gerson and R. S. C. Smart, PCCP 2012, 14, 2434-2442; b) M. T. Greiner, M. G. Helander, Z.-B. Wang, W.-M. Tang and Z.-H. Lu, J. Phys. Chem. C 2010, 114, 19777-19781.

[9] a) C. D. Wagner, Anal. Chem. 1972, 44, 967-973; b) S. W. Gaarenstroom and N. Winograd, The Journal of Chemical Physics 1977, 67, 3500-3506; c) C. D. Wagner, L. H. Gale and R. H. Raymond, Anal. Chem. 1979, 51, 466-482. 
[10] 2000.

[11] a) L. Grządziel, M. Krzywiecki, A. Szwajca, A. Sarfraz, G. Genchev and A. Erbe, J. Phys. D: Appl. Phys. 2018, 51, 315301; b) D. F. Cox, T. B. Fryberger and S. Semancik, Phys. Rev. B 1988, 38, 2072-2083.

[12] M. Fingerle, S. Tengeler, W. Calvet, W. Jaegermann and T. Mayer, J. Electrochem. Soc. 2020, $167,136514$.

[13] A. M. Ganose and D. O. Scanlon, Journal of Materials Chemistry C 2016, 4, 1467-1475.

[14] a) S. Sagadevan, S. Rajesh and I. Das, Materials Today: Proceedings 2017, 4, 4123-4129; b) S. Hüfner, Adv. Phys. 1994, 43, 183-356; c) M. H. Raza, N. Kaur, E. Comini and N. Pinna, ACS Appl. Mater. Interfaces 2020, 12, 4594-4606.

[15] a) A.-K. Elger and C. Hess, Angew. Chem. Int. Ed. 2019, 58, 15057-15061; b) D. Degler, S. Wicker, U. Weimar and N. Barsan, J. Phys. Chem. C 2015, 119, 11792-11799; c) A. Staerz, T. Suzuki, U. Weimar and N. Barsan in 12 - SnO2: The most important base material for semiconducting metal oxide-based materials, (Ed. M. O. Orlandi), Elsevier, 2020, pp. 345-377; d) M. Budde, C. Tschammer, P. Franz, J. Feldl, M. Ramsteiner, R. Goldhahn, M. Feneberg, N. Barsan, A. Oprea and O. Bierwagen, J. Appl. Phys. 2018, 123, 195301.

[16] a) J. Zhang, D. Zeng, Q. Zhu, J. Wu, Q. Huang, W. Zhang and C. Xie, PCCP 2016, 18, 53865396; b) N. Barsan and U. Weimar, J. Electroceram. 2001, 7, 143-167.

[17] a) P. A. Russo, N. Donato, S. G. Leonardi, S. Baek, D. E. Conte, G. Neri and N. Pinna, Angew. Chem. Int. Ed. 2012, 51, 11053-11057; b) C. Marichy, P. A. Russo, M. Latino, J.-P. Tessonnier, M.-G. Willinger, N. Donato, G. Neri and N. Pinna, J. Phys. Chem. C 2013, 117, 19729-19739.

[18] H. Ogawa, M. Nishikawa and A. Abe, J. Appl. Phys. 1982, 53, 4448-4455.

[19] D. Degler, U. Weimar and N. Barsan, ACS Sens. 2019, 4, 2228-2249.

[20] a) A. Staerz, X. Gao, F. Cetmi, Z. Ming, U. Weimar, T. Zhang and N. Barsan, ACS Appl. Mater. Interfaces 2020, 12, 21127-21132; b) P. Karnati, S. Akbar and P. A. Morris, Sens. Actuators, B 2019, 295, 127-143.

[21] M. C. Horrillo, J. Gutiérrez, L. Arés, J. I. Robla, I. Sayago, J. Getino and J. A. Agapito, Sensors and Actuators A: Physical 1994, 42, 619-621.

[22] a) L.-Y. Zhu, K. Yuan, J.-G. Yang, H.-P. Ma, T. Wang, X.-M. Ji, J.-J. Feng, A. Devi and H.-L. Lu, Sens. Actuators, B 2019, 290, 233-241; b) S. Mills, M. Lim, B. Lee and V. Misra, ECS Journal of Solid State Science and Technology 2015, 4, S3059-S3061.

[23] a) S. Seo, I. J. Park, M. Kim, S. Lee, C. Bae, H. S. Jung, N.-G. Park, J. Y. Kim and H. Shin, Nanoscale 2016, 8, 11403-11412; b) Q. Xu, Z. Zhang, X. Song, S. Yuan, Z. Qiu, H. Xu and B. Cao, Sens. Actuators, $B$ 2017, 245, 375-385.

[24] S. Ng, J. Prášek, R. Zazpe, Z. Pytlíček, Z. Spotz, J. R. Pereira, J. Michalička, J. Přikryl, M. Krbal, H. Sopha, J. Hubálek and J. M. Macák, ACS Appl. Mater. Interfaces 2020, 12, 33386-33396. 